


\section{GUIA DO USUÁRIO DO DIGITAL OBJECT IDENTIFIER}

RONNIE FAGUNDES DE BRITO

MILTON SHINTAKU

SUELY DE BRITO CLEMENTE SOARES

CLAUDIANE WEBER

Brasília

2016 
Instituto Brasileiro de Informação em Ciência e Tecnologia (Ibict)

Esta obra é licenciada sob Atribuição CC BY 4.0, sendo permitida a reprodução parcial ou total desde que mencionada a fonte.

\section{(c) (1)}

\section{Editor Executivo}

Ramón Martins Sodoma da Fonseca

\section{Capa / Ilustrações}

Andréa Maria de Castro Santos Fleury Curado

\section{Normalização}

Ingrid Torres Schiessl - Classificação e catalogação

Priscilla Mara Bermudes Araújo - Ficha catalográfica

\section{Editoração eletrônica}

Linceu Editorial Ltda

www.linceu.com.br

B294

Guia do Usuário do Digital Object Identifier / Ronnie Fagundes de Brito ... [et l.]. - Brasília : Instituto Brasileiro de Informação em Ciência e Tecnologia, 2015.

$62 \mathrm{f}$ : : il. ; color.

ISBN: 978-85-7013-113-3.

doi: 10.21452/978-85-7013-112-6

I. Brito, Ronnie Fagundes de. II. Shintaku, Milton. III. Soares, Suely de Brito Clemente. IV. Weber, Claudiane. V. Instituto Brasileiro de Informação em Ciência e Tecnologia. VI. Título.

CDU 02:004

\section{Instituto Brasileiro de Informação em Ciência e Tecnologia (Ibict)}

Setor de Autarquias Sul (SAUS)

Quadra 05 Lote 06, Bloco $\mathrm{H}-5^{\circ}$ Andar

Cep: 70070-912 - Brasília, DF

Telefones: 55(61) 3217-6360 /

55(61) 3217-6350

www.ibict.br
Rua Lauro Muller, 455 - 4 Andar - Botafogo Cep: 22290-160 - Rio de Janeiro, RJ Telefone: 55(21) 2275-0321

Fax: 55(21) 2275-3590

http://www.ppgci.ufrj.br 


\section{SUMÁRIO}

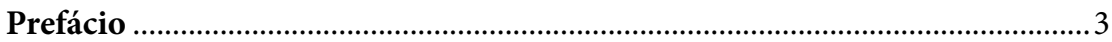

Introdução ..........................................................................................................

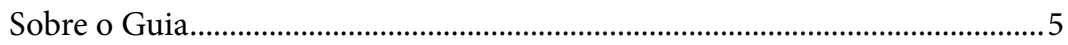

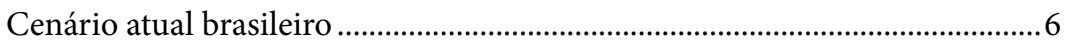

Público-alvo ...................................................................................................

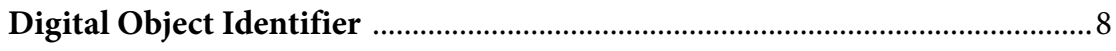

Perguntas frequentes.....................................................................................

O que é o DOI? ...............................................................................................

Para que serve? ...............................................................................

Por que usar? ...............................................................................

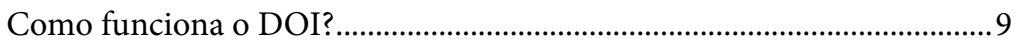

Agências de registro ......................................................................................... 12

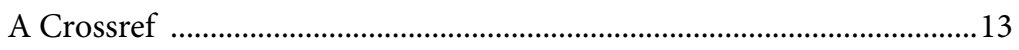

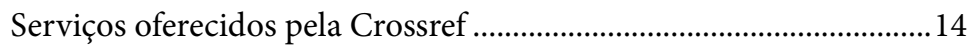

O Convênio CROSSREF-ABEC-IBICT ........................................................16

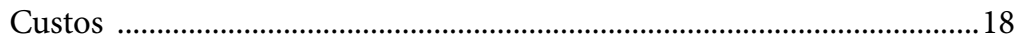

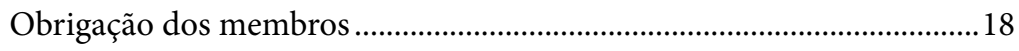

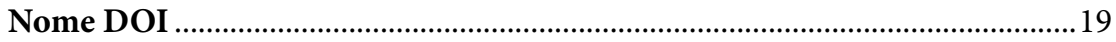

Sugestões para nomes DOI.....................................................................20

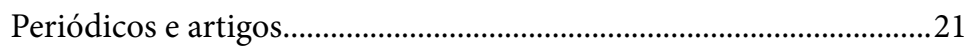

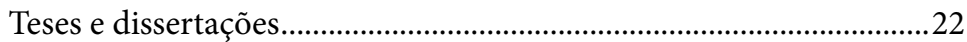


Eventos e artigos de eventos ..................................................................23

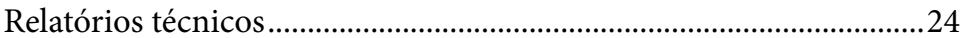

Livros e capítulos de livros ....................................................................25

Como indicar o DOI nas referências..............................................................27

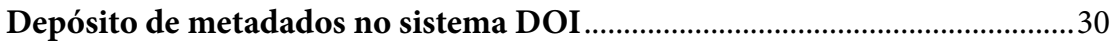

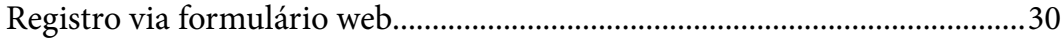

Registro via Open Journal Systems ....................................................................

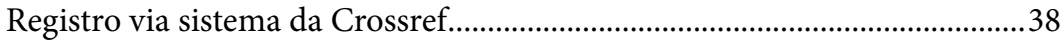

Acompanhamento do depósito ..............................................................................4

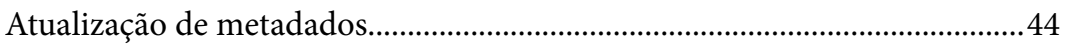

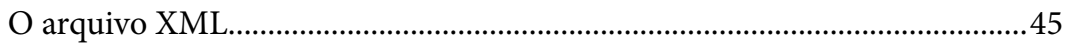

Validação do arquivo XML ................................................................................4

Metadados sobre referências..............................................................................4

Resolução múltipla.............................................................................................49

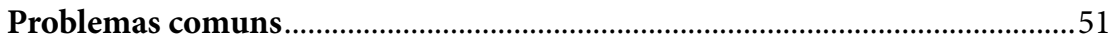

Propriedade do prefixo.......................................................................................51

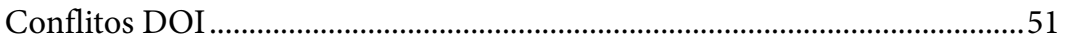

Nomes DOI inválidos após o depósito...............................................................

Data de publicação não cadastrada......................................................................52

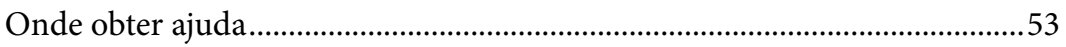

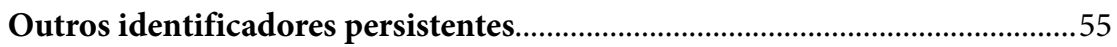

Vantagens ao autor .............................................................................................5 


\section{PREFÁCIO}

O Digital Object Identifier (DOI) ${ }^{\circledR}$ é um identificador internacionalmente aceito e, cada vez mais, tem se tornado essencial, principalmente para documentos digitais. Por outro lado, sabemos ainda que, no Brasil, muitos de nossos periódicos ainda não o adotam ou apresentam grandes dificuldades na sua gestão.

Diante desse quadro, a união de esforços da Associação Brasileira de Editores Científicos (ABEC) e do Instituto Brasileiro de Informação em Ciência e Tecnologia (Ibict) gerou o Guia do Usuário do Digital Object Identifier. Este Guia nasceu da importância de se apoiar os editores brasileiros na adoção e uso desse identificador.

Trata-se de um guia prático e atualizado, com informações úteis e muito apropriadas às ações das duas instituições envolvidas no trabalho de apoio aos editores científicos. Supre as necessidades atuais dos editores no que se refere a informações básicas, apresentando-se como uma boa opção de documentação técnica sobre o DOI.

As informações iniciais, contemplando as agências e sugestões de nomes DOI, reforçam a abrangência desse identificador, apresentando o seu uso em variada tipologia documental, o que condiz com as necessidades das instituições brasileiras que publicam diversos trabalhos. Além disso, expande a compreensão sobre esse identificador, suas agências e serviços, além de ressaltar o acordo entre Crossref, ABEC e Ibict.

$\mathrm{Na}$ apresentação sobre como indicar o DOI nas referências, os autores reforçam o uso do identificador, apoiando os usuários a citar documentos que possuam DOIs já atribuídos, além de indicar sua importância. O Guia responderá às frequentes dúvidas sobre as normas de citação e as mudanças fomentadas pela inclusão da tecnologia no processo da criação de novos conhecimentos.

O passo-a-passo para depósito de metadados no sistema DOI apoia os editores e técnicos na adaptação dos procedimentos, com vistas à adoção desse 
identificador. Apresenta ainda a forma de executar cada etapa destinada a tornar válidos os DOIs atribuídos às publicações.

O Guia relaciona ainda, os problemas mais comuns que os editores e técnicos já enfrentaram para atribuir o DOI e como resolvê-los. Inclui também dados sobre a relação do Open Research and Contributor ID (ORCID) e o DOI, que tem se revelado uma tendência mundial.

Reforçamos, desse modo, o compromisso da ABEC como representante oficial da Crossref no Brasil, em apoiar a atribuição do DOI em todas as publicações nacionais fomentando esta publicação a fim de atender os editores brasileiros. Devemos ressaltar o esforço do time de desenvolvimento do Ibict, o qual foi essencial para a esta realização, numa parceria produtiva em prol da visibilidade da produção científica nacional.

\section{Rui Seabra Ferreira Junior}

Presidente da ABEC 


\section{INTRODUÇÃO}

O Ibict, por meio da Coordenação de Articulação, Geração e Aplicação de Tecnologia (COAT), em parceria com a ABEC, desenvolveu este Guia do Usuário do Digital Object Identifier. O DOI, como forma de apoiar e promover o uso dessa tecnologia no contexto das publicações técnicas e científicas brasileiras.

Este Guia é mais um resultado do convênio firmado entre Crossref, ABEC e Ibict, que tem por objetivo difundir, apoiar e facilitar a utilização do DOI no Brasil, contribuindo com a inserção internacional da produção científica do país. Sabe-se que, cada vez mais, o mundo científico tem aderido a identificadores aceitos internacionalmente como forma padronização, com o propósito de facilitar a recuperação, entre outras ações, da documentação científica disponível na web.

Da mesma forma, alinha-se às iniciativas brasileiras, como as do Conselho Nacional de Desenvolvimento Científico e Tecnológico (CNPq), que adotou o DOI como identificador no Currículo Lattes, apresentando-se como uma fonte de informação atual, em conformidade com as necessidades dos usuários. Além disso, contribui para suprir a deficiência de documentação técnica sobre esse assunto no Brasil, na medida em que explicita um tema pouco explorado, mas de muito interesse, pela comunidade científica.

O Guia tem como propósito auxiliar na adoção de uma tecnologia mundialmente utilizada, atuando tanto como orientador quanto como documento de consulta, na medida em que contempla os vários aspectos relacionados à utilização do DOI e abrange os principais tópicos sobre esse identificador e sua aplicação.

\section{SOBRE O GUIA}

Este Guia tem por principal objetivo apoiar os usuários brasileiros do DOI quanto a sua utilização - sejam editores, autores ou leitores - em todo o fluxo de publicação que envolva o uso desse identificador. Para tanto, 
descreve o sistema de identificadores digitais de objetos DOI, apresentando os conceitos associados ao sistema, as vantagens de seu uso e os detalhes de seu funcionamento.

Desse modo, expõe de forma sucinta os tópicos de interesse ao descrever a estrutura de um nome DOI, processos, mecanismos e aspectos técnicos envolvidos no seu uso, além de serviços associados, procurando atender a necessidade de informação e contribuindo para a melhor aplicação desse identificador.

O Guia também traz casos de aplicação do DOI em diferentes casos, como identificação de artigos científicos, conjuntos de dados e asserção de direitos autorais, apresentando todas as possibilidades desse identificador, que tem sido relacionado apenas com artigos. Além disso, procura atender todos os usuários que necessitem ofertar o DOI a publicações, principalmente no ambiente heterogêneo da Internet.

Espera-se contribuir, por meio deste Guia, com o processo de adoção e utilização de identificadores internacionalmente aceitos e, com isso, apoiar a internacionalização das publicações brasileiras, no que tange à identificação dos documentos, bem como auxiliar os editores brasileiros na adequação de suas publicações quanto à utilização do DOI, uma vez que se carece de documentação técnica de apoio.

\section{CENÁRIO ATUAL BRASILEIRO}

O sistema DOI foi proposto em 1996 e iniciado em 1998 pela International DOI Foundation ${ }^{1}$, oferecendo principalmente mecanismos de contingência à instabilidade das localizações de documentos no ambiente da Internet. Permite realizar vinculações entre documentos on-line, sem que as mudanças nos locais prejudiquem a navegabilidade entre eles.

Com isso, a adoção do DOI por parte dos editores agiliza o processo de preenchimento dos formulários do Currículo Lattes e melhora a acurácia das informações, além de validá-las, no sentido da coleta de informações fornecidas pelos editores de uma base confiável. Isso é possível porque a Crossref e outras agências mantêm bases de dados sobre os artigos.

1.http://mww.doi.org/ 
Em 2014, a ABEC firmou, junto à Crossref, um acordo para representação no qual a aquisição do DOI é facilitada. Com isso, viabiliza-se a obtenção desse identificador de forma mais econômica, pois os editores brasileiros ficam isentos da anuidade da Crossref, pagando apenas os DOIs atribuídos aos objetos digitais. $\mathrm{O}$ convênio é aberto para sócios e não sócios, de forma a ampliar a adoção.

O acordo conta com o Ibict no papel de suporte aos usuários, ofertando apoio técnico a todos. Esse apoio é oferecido de várias formas, com destaque à produção de informações disponíveis na Internet, por meio de páginas Wiki, fóruns e outros.

As ações do CNPq, da ABEC e do Ibict têm por objetivo o aumento da visibilidade da produção científica nacional com a utilização de identificador internacional. Nesse sentido, alinha-se ao interesse na utilização do DOI por parte dos editores, na medida em que grande parte da produção científica está disponível na Internet e requer identificação segura.

\section{PÚBLICO-ALVO}

O Guia é voltado a pesquisadores, editores de revistas científicas, bibliotecários e demais públicos interessados, esclarecendo de forma objetiva e direta questionamentos levantados pela comunidade atendida pelo convênio Crossref-ABEC-Ibict. Assim, muito do conteúdo presente neste documento tem origem nas dúvidas dos usuários recebidas pelo Ibict.

Para os editores, público-alvo principal, o Guia foca nos processos associados ao sistema DOI, como a atribuição de nomes DOI e o depósito dos respectivos metadados. O Guia é voltado para as principais atividades dos editores no processo de atribuir DOIs aos objetos, independentemente do tipo, procurando ser o mais abrangente possível, mesmo que possua certo direcionamento para artigos de revistas. Fornece também informação sobre como citar documentos com DOI, apresentando as facilidades que esse identificador oferece, o que interessa a todos os envolvidos na cadeia de produção científica. 


\section{DIGITAL OBJECT IDENTIFIER}

O DOI (traduzido como "Identificador Digital de Objetos") é um sistema que permite a identificação, localização e descrição unívoca de entidades digitais físicas ou abstratas. Atualmente, tem sido muito adotado na Internet, devido, principalmente, às necessidades de padronização e preservação das informações contidas nesse ambiente.

Um DOI é atribuído a um determinado conteúdo por um editor ou instituição responsável. Mesmo que se alterem as questões de direitos patrimoniais ou localização, o DOI deve permanecer o mesmo. Uma vez atribuído um DOI, não se pode removê-lo ou alterá-lo, mas é possível mudar as informações vinculadas a um DOI, fazendo um novo depósito de informações, mantendo o DOI e alterando os metadados.

Cada agência de registro pode definir regras específicas quanto a seus identificadores. No caso, os DOIs da Crossref são únicos e ofertados a trabalhos finais, não sendo recomendado atribuir DOIs a versões ou trabalhos derivados. Documentos em formatos diferentes devem compartilhar o mesmo DOI, sendo que artigos, livros ou outros documentos devem assinalar o mesmo DOI independentemente do suporte impresso ou digital.

Entretanto, reconhecem-se casos em que há necessidade de ofertar mais que um DOI para trabalhos publicados em diferentes veículos, como uma republicação. Se um artigo é publicado em revista e, posteriormente, torna-se capítulo de livro, por exemplo, possui metadados com diferenças de conteúdo suficientes para possuir DOIs distintos.

Essencialmente, é um sistema que associa um nome DOI a um conjunto de metadados, de modo que, a partir de determinado nome, seja possível acionar serviços baseados nos metadados associados. Forma-se assim, uma base de dados com DOIs e metadados, possibilitando a recuperação das informações de maneira interoperável, por meio de um serviço aberto, acessível a todos.

Nesse sentido, é possível atribuir o DOI a qualquer objeto, desde que esteja finalizado em formas hierárquicas e granulares. Pode ser ofertado a uma obra 
no todo e/ou suas partes, desde que seja possível descrevê-las conforme as necessidades do sistema, principalmente quanto à questão de autoria. Essa granularidade não apresenta conflitos de identificação.

\section{PERGUNTAS FREQUENTES}

\section{O que é o DOI?}

O DOI é um sistema que engloba diferentes subsistemas para o depósito de metadados e a resolução dos nomes DOI. De forma direta, consiste em um par composto por identificador e metadados, em que os metadados podem ser recuperados a partir do identificador. Trata-se de um identificador persistente, único e publicado que gestores de conteúdo vinculam a objetos físicos ou digitais, o que possibilita ofertar serviços e garantir a propriedade intelectual, principalmente para objetos digitais disponíveis na Internet.

\section{Para que serve?}

O DOI atua na identificação e descrição de entidades físicas ou abstratas, reais ou virtuais, digitais ou analógicas. Entre os elementos descritivos estão localização, dados de propriedade intelectual e relacionamento com outros objetos, a partir dos quais uma série de serviços pode ser implementada.

\section{Por que usar?}

O uso de um identificador para entidades digitais, como artigos científicos ou conjuntos de dados, permite a implementação de serviços associados aos metadados depositados junto ao identificador. Serviços como localização, gestão de direitos autorais, métricas de acesso e de referenciamento são úteis e garantem acesso ao texto integral, da mesma forma em que se preservam os metadados em base de dados, ofertando-se certa segurança em caso de contingência e alinhando-se com as necessidades de curadoria de conteúdos digitais na Internet.

\section{Como funciona o DOI?}

O sistema DOI consiste numa federação de agências de registro de metadados, as quais operam sob o padrão definido pela norma ISO 26324 (2012). Essencialmente, possibilita a atribuição de um identificador, denominado 
nome DOI, aliado ao depósito de metadados, para a posterior localização do objeto, por meio desse identificador. Com isso, é possível encontrar um recurso ou suas informações na web.

Do ponto de vista de seus usuários, o sistema DOI opera em dois momentos distintos: depósito de metadados e resolução do nome DOI.

No primeiro momento, o editor deposita os metadados associados aos objetos identificados pelos nomes DOI. Nessa etapa, os metadados são validados e processados por uma agência de registro - entre elas a Crossref - e, quando devidamente certificados, passam a constar no sistema DOI, no qual as agências de registro são federadas, conforme a Figura 1.

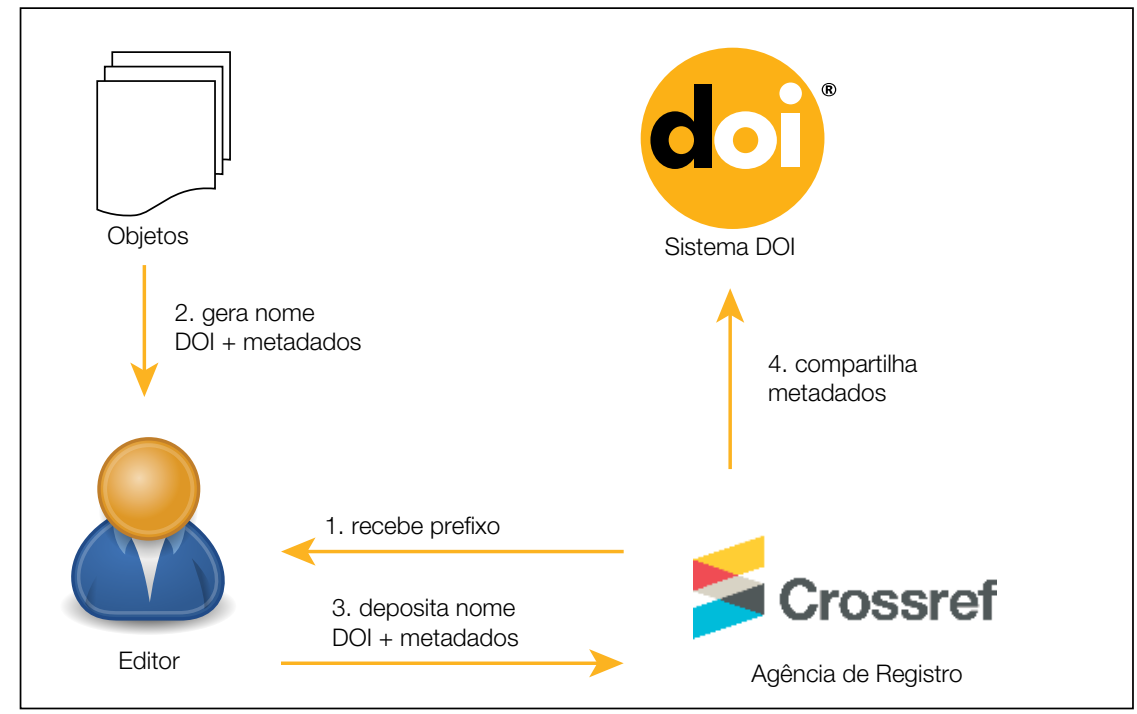

Figura 1 - Depósito de metadados no sistema DOI.

No segundo momento (Figura 2), os leitores acionam um serviço de resolução de nomes tendo como parâmetro determinado nome DOI, o qual retornará o conjunto de metadados associados ao objeto identificado pelo mesmo. Esse tipo de acionamento ocorre de forma transparente ao se clicar em um link com nome DOI. ${ }^{2}$

2.Por exemplo, http://doi.org/10.1000/182. 


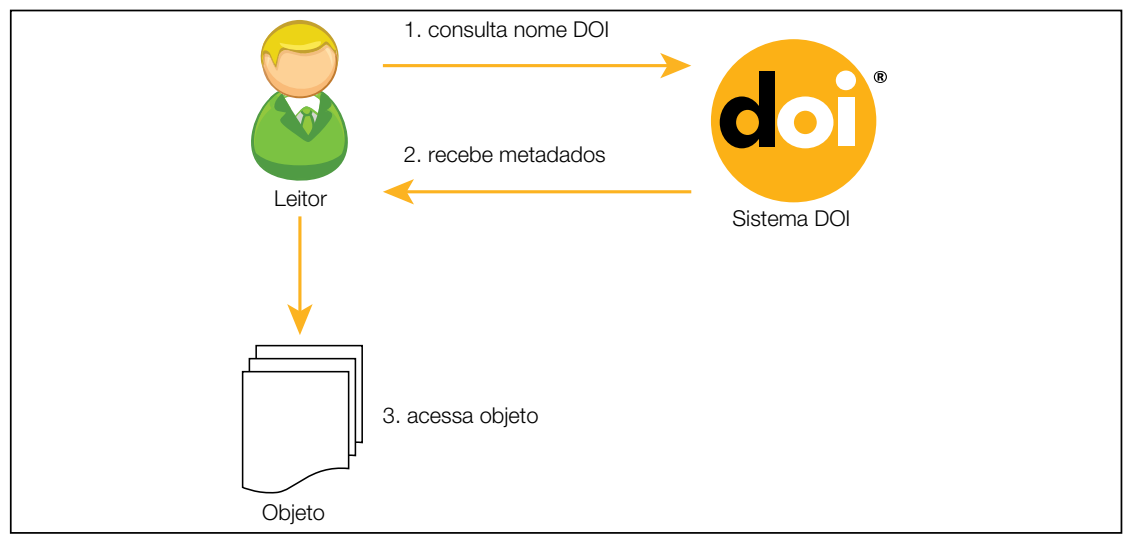

Figura 2 - Consulta de nome DOI.

Diferentes serviços podem ser realizados a partir desses metadados, sendo que o principal é o direcionamento para a localização do objeto na web, acionado, por exemplo, por um formulário (Figura 3 ) onde se insere o nome DOI e o usuário é direcionado ao endereço do objeto.

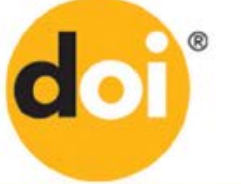

HOME I HANDBOOK I FACTSHEETS I FAOS I RESOURCES I USERS I NEWS I MEMBERS AREA

\section{Resolve a DOI Name}

dol:

Go

Type or paste a DOI name into the text box. Click Go. Your browser will take you to a Web page (URL) associated with that DOI name.

Send questions or comments to doi-help@doi.org.

Further documentation is avallable here.

\section{DOI System Proxy Server Documentation}

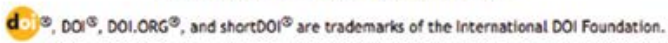

Figura 3 - Interface de resolução de nomes $\mathrm{DOI}^{3}$.

\footnotetext{
3.http://mun.dx.doi.org
} 


\section{AGÊNCIAS DE REGISTRO}

Os nomes DOI podem ser registrados em diferentes agências, as quais se dispõem a gerenciar esses identificadores e ofertar serviços. Assim, as agências de registro que fazem parte do sistema DOI são responsáveis pela inserção e armazenamento dos metadados depositados.

Para ofertar localização segura e outros serviços na Internet, há outras opções como o sistema Handle ${ }^{4}$; entretanto, o sistema DOI se diferencia por ter várias agências, que inserem uma camada gerencial e organizacional, comprometendo-se com aspectos de governança, persistência, consistência e de outros serviços. O sistema Handle, por sua vez, se restringe a aspectos mais técnicos, como a preservação de metadados de localização.

Diferentes agências de registro atuam de forma federada dentro do sistema, cada uma com políticas específicas a sua área de atuação, mas coerentes com o sistema DOI. Podem-se caracterizar algumas por suas respectivas frentes de atuação e quantidade de registros, conforme a Tabela 1.

Tabela 1 - Agências de registro DOI e respectivos campos de atuação5.

\begin{tabular}{|c|c|c|}
\hline . & & $\begin{array}{l}\text { Registra nomes DOI de documentos } \\
\text { escritos em chinês tradicional. }\end{array}$ \\
\hline & & $\begin{array}{l}\text { Registra nomes DOI de artigos técnicos } \\
\text { e científicos, além de capítulos de livros, } \\
\text { anais de conferências, normas, teses e } \\
\text { dissertações. }\end{array}$ \\
\hline Dat & & $\begin{array}{l}\text { Permite o depósito de nomes DOI } \\
\text { referentes a conjuntos de dados. }\end{array}$ \\
\hline$(6$ & $\begin{array}{l}\text { China Knowledge Resource } \\
\text { Integrated Database }\end{array}$ & $\begin{array}{l}\text { Registro de nomes DOI para artigos } \\
\text { de revistas, teses e dissertações, } \\
\text { anais de conferências e anuário } \\
\text { escritos em chinês. }\end{array}$ \\
\hline
\end{tabular}

Continua...

\footnotetext{
4.https://wmw.handle.net/

5.http://muw.doi.org/registration_agencies.html
} 
Tabela 1 - Continuação.

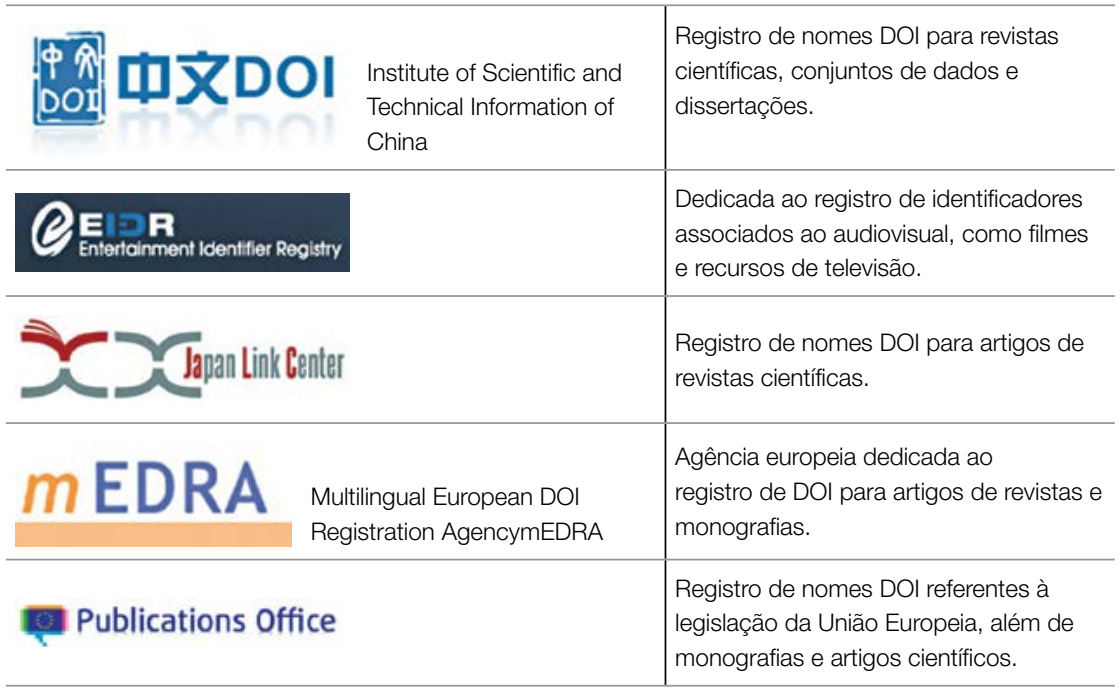

\section{A Crossref}

A Crossref é uma organização sem fins lucrativos criada no final de 1999 com o propósito de atender a comunidade com serviços seguros, oficializados e inovadores, de forma a apoiar a persistência dos identificadores com uma infraestrura sustentável que proporciona a comunicação científica. Com isso, promove o desenvolvimento e a utilização compartilhada de tecnologias inovadoras para acelerar e facilitar a pesquisa científica.

A organização restringe sua operação à identificação e manutenção de informações (metadados) de documentação científica, com uma base de dados que possibilita ligar referências digitais. Não mantém textos completos, apenas as referências, com destaque para a questão de autoria e localização. Assim, assegura confiabilidade na citação de documentos disponibilizados na Internet.

No início do ano 2000, foi criado o Publishers International Linking Association, Inc. (PILA) para operar a Crossref. Trata-se de uma associação de editores e acadêmicos provenientes do mundo todo com o propósito de apoiar a infraestrutura informacional e as funcionalidades editoriais. Com isso, foram resolvidas as questões financeiras e administrativas, apoiando-se os serviços fornecidos pela Crossref. 


\section{Serviços oferecidos pela Crossref}

As agências de registro oferecem Interfaces de Programação de Aplicações (APIs), que dão acesso a funcionalidades associadas aos metadados e identificadores, mantidos por essas agências. Essas APIs permitem o desenvolvimento de diversos serviços, como busca de informações, controle de autoridade e de versões, todos baseados nas informações mantidas pela agência.

A Crossref oferta vários serviços associados ao DOI e aos seus metadados, como apresentado na Figura 4, de forma a contribuir com a comunidade acadêmica.

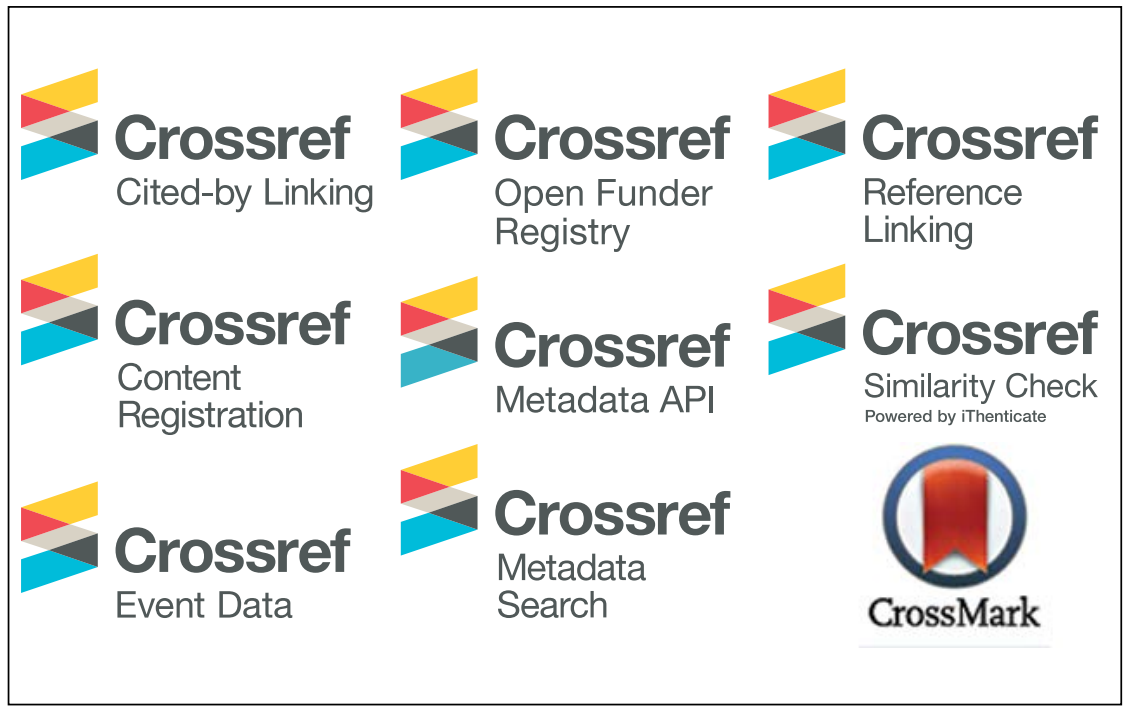

Figura 4 - Diferentes serviços oferecidos pela Crossref.

O serviço Cited By Linking permite recuperar os documentos que citam determinado artigo. Desse modo, torna-se útil no desenvolvimento de ferramentas métricas, referentes à visibilidade do artigo, mesmo que nativamente não se vincule especificamente a nenhuma métrica. Da mesma forma, é interessante aos autores e pesquisadores saber quais outros documentos científicos estão citando determinado conteúdo.

O Similarity Check (anteriormente CrossCheck), por sua vez, possibilita conferir a autenticidade de determinado documento, além de oferecer notificações sobre versões atualizadas do artigo, como atualizações ou erratas. É um serviço 
eficiente para os editores quanto ao trabalho interminável de detectar plágios, por exemplo. Além disso, é apoiado em parte pela ferramenta iThenticate 6 , juntamente com a base de dados da Crossref.

O CrossMark é um serviço de alerta voltado aos gestores de conteúdo, mantendo-os atualizados em caso de versionamento e autenticidade. Possibilita que usuários saibam se o documento acessado é a última versão e se há outras versões disponíveis. Para editores utilizarem os serviços, um logo do CrossMark é adicionado aos documentos e, ao ser clicado, apresenta uma página com informações sobre atualizações ou erratas referentes ao documento, conforme ilustrado na Figura 5.

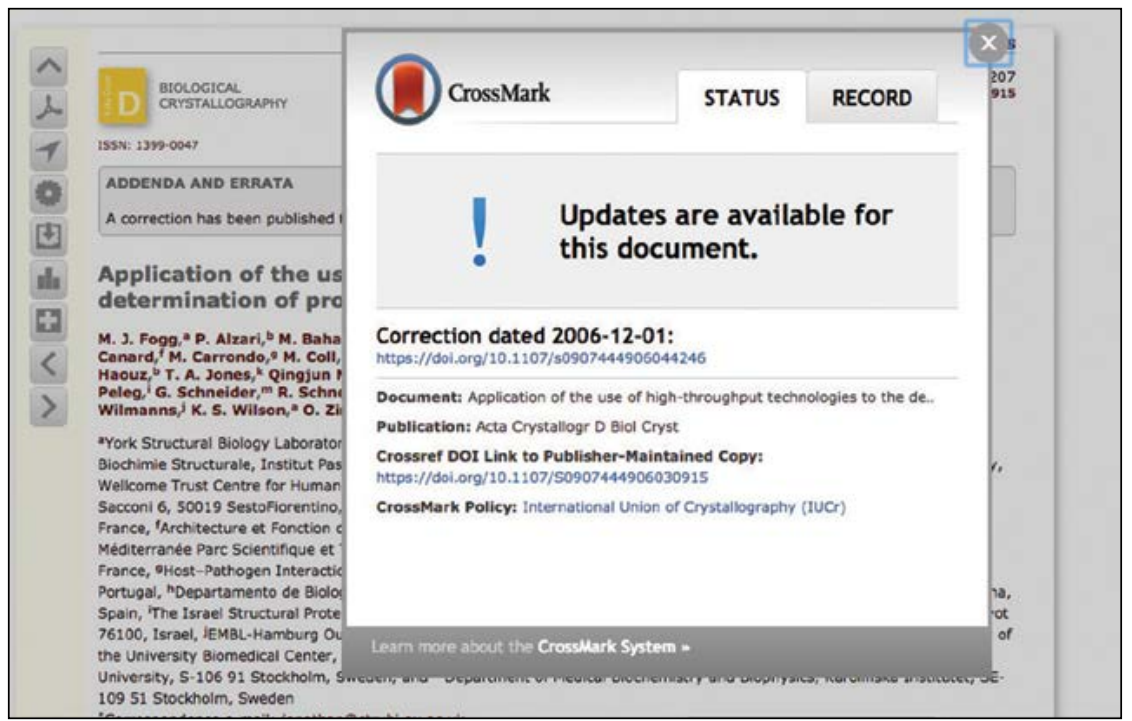

Figura 5 - Tela com as informações sobre atualizações fornecidas pelo serviço CrossMark?.

Já o Open Funder Registry oferece uma base de dados pública sobre recursos de apoio à pesquisa, permitindo relacionar publicações com os respectivos agentes de fomento. Com isso, possibilita que seus usuários conheçam todos os trabalhos apoiados por determinada instituição de fomento, por exemplo.

\footnotetext{
6.http://mw.ithenticate.com/

7.http://journals.iucr.org/d/issues/2006/10/00/gx5096/index.html
} 


\section{O CONVÊNIO \\ CROSSREF-ABEC-IBICT}

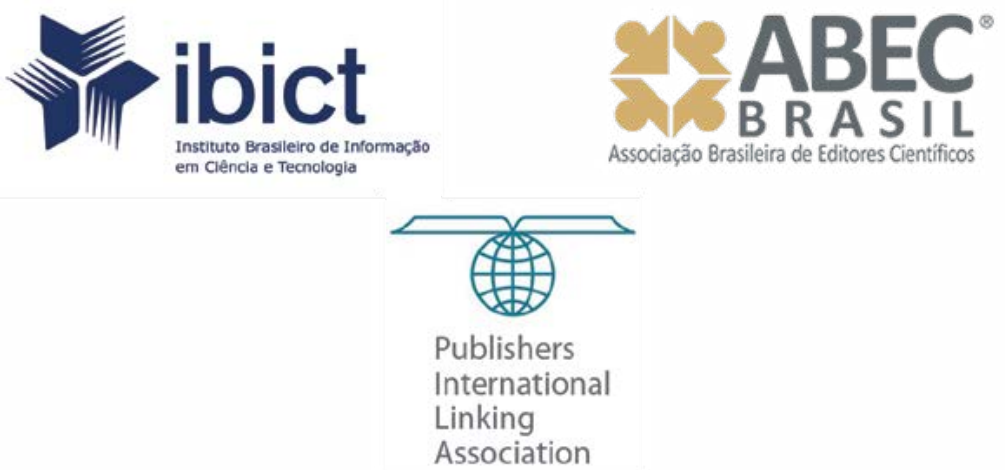

Como forma de apoiar a produção científica brasileira, fomentando sua internacionalização, no final de 2014, ABEC, Crossref e Ibict estabeleceram um acordo para facilitar a obtenção e o depósito de nomes DOI. Essa ação teve reflexo direto na visibilidade da produção, visto que o nome DOI é um identificador internacionalmente aceito e que grandes editores vinculam suas publicações ao mesmo. Da mesma forma, o acordo apoia os editores e autores brasileiros a se adequarem às determinações do $\mathrm{CNPq}$, o qual utiliza o sistema DOI na plataforma Lattes. Essa adesão facilita o processo de cadastramento da produção científica dos autores, além de potencializar a normalização dos metadados e garantir a autenticidade das informações prestadas, validando-as.

Nesse acordo, a ABEC assume o papel de Sponsoring Affiliate e o Ibict, o papel de suporte técnico. Desse modo, a ABEC é responsável pelo pagamento da anuidade de afiliação à Crossref em nome de todas as instituições brasileiras que optarem pela representação, desde que classificadas como instituições ou associações não comerciais e sem fins lucrativos.

No contexto desse acordo, as instituições permanecem membros da Crossref e têm todos os seus direitos e deveres mantidos; além disso, o processo de registro de nomes DOI além da isenção da anuidade de afiliação ao Crossref. $\mathrm{O}$ 
acordo proporciona economia aos editores, pois não precisam mais pagar a anuidade à Crossref, o processo de pagamento dos DOIs depositados é facilitado, com pagamento em moeda nacional diretamente à $\mathrm{ABEC}$.

Segundo o portal da ABEC (2016),

As instituições continuarão atribuindo DOIs às suas publicações de forma independente e usando o prefixo já definido. O pagamento referente aos DOIs atribuídos é a novidade do processo, pois a Crossref enviará a fatura diretamente para a $\mathrm{ABEC}$, que efetuará o pagamento. Posteriormente, a ABEC repassará a cobrança para cada instituição com as opções de pagamento no Brasil: boleto bancário, depósito em conta, notas de empenho ou cartão de crédito. Assim, não haverá qualquer necessidade de envio de recursos financeiros ao exterior por parte das instituições representadas pela ABEC.

Importante ressaltar que para a atribuição dos DOIs, é necessário que a instituição seja afiliada ao Crossref. As instituições que já são afiliadas e que quiserem aderir ao acordo terão que indicar a $A B E C$ como sua representante por meio do termo; "Represented Member Agreement". As instituições que não são afiliadas ao Crossref e quiserem aderir ao acordo, devem solicitar o mesmo termo, que neste caso servirá tanto para fins de afiliação como para representação. Após análise, a solicitação será submetida ao Crossref, sendo que este poderá aprová-la ou não. Em caso de aprovação serão fornecidos o prefixo e a conta para acesso aos serviços do Crossref. Assim que a instituição se tornar representada, um e-mail explicativo será enviado informando como contatar o Ibict para suporte técnico.

Os custos para atribuição dos DOIs serão os mesmos praticados pelo Crossref. Para as instituições associadas à $\mathrm{ABEC}$ não será repassada nenhuma taxa adicional. Para as instituições não associadas à $\mathrm{ABEC}$ ou em casos de inadimplência com a ABEC (anuidades anteriores) será cobrada uma taxa administrativa. Maiores informações sobre esses valores poderão ser obtidas na página da $\mathrm{ABEC}$ na internet. 


\section{Custos}

Para membros representados pela $\mathrm{ABEC}$, os custos de registro de nomes DOI seguem a Tabela 2 .

Tabela 2 - Custos de registro de nomes DOI.

\begin{tabular}{l|l}
\hline Objeto & Custo \\
\hline Artigos, livros, teses e dissertações & US\$ 1 (um dólar americano) \\
\hline Artigos antigos (back file) & US\$ 0.15 (quinze centavos de dólar) \\
\hline Título de periódico & Gratuito \\
\hline Capítulos de livros & US\$ 0.25 (vinte e cinco centavos de dólar) \\
\hline Conjuntos de dados e elementos & US\$ 0.06 (seis centavos de dólar) \\
\hline
\end{tabular}

Os valores são os mesmos praticados pela Crossref, sendo que a $A B E C$ não cobra a intermediação para membros afiliados. A cobrança é feita trimestralmente, para os DOIs atribuídos no período, para cada membro representado (instituição ou editor).

\section{Obrigação dos membros}

Ao participarem, espera-se que os membros da Crossref:

- Construam e operem os sistemas necessários para compor arquivos XML de depósito de metadados à Crossref;

- Adicionem os links DOI (quando disponíveis) nas referências contidas nos artigos publicados;

- Regularmente monitorem suas transações com a Crossref, identificando e corrigindo eventuais erros;

- Permaneçam vigilantes para manter metadados dos nomes DOI atualizados, particularmente, a Uniform Resource Location (URL) do recurso;

- Revejam os relatórios da Crossref emitidos aos membros solucionando eventuais erros identificados;

- Usem esforços economicamente razoáveis para tornar o conteúdo disponível e garantir a persistência de ligações através de um arquivamento autorizado no caso de o editor não ser mais capaz de acolher o seu conteúdo. 
O nome DOI é a forma padrão de se denominar o identificador atribuído aos objetos, consistindo de uma sequência de caracteres com formação única e que remete ao objeto como um registro formal digital. Por ser único, cabe ao depositante (editor ou metaeditor) gerar nomes DOI únicos, da mesma forma que cabe à agência (neste caso, a Crossref) não aceitar nomes DOI duplicados.

O nome DOI é regulamentado conforme o padrão ANSI/NISO Z39.84-2000 de 2010, como parte do padrão ISO 26324, também de 2010. O nome é formado por duas partes: um prefixo e um sufixo, separados por uma barra “", conforme a Figura 6. O prefixo indica o membro Crossref (por exemplo, a Universidade de São Paulo - USP) e o sufixo particulariza o objeto a ser identificado (revista InCID, volume 5, número 2, artigos das páginas 34 a 50). O nome DOI pertence aos chamados Handles, links unívocos que remetem a objetos.

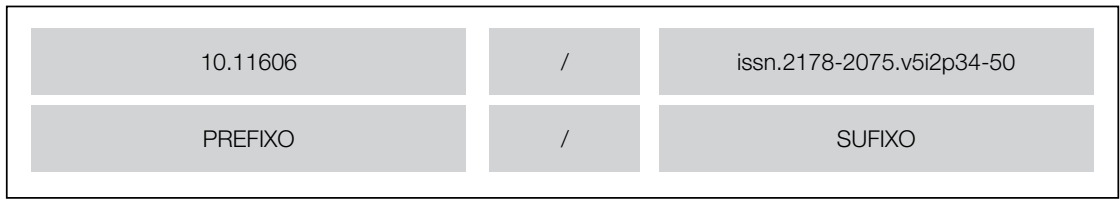

Figura 6 - Exemplo de nome DOI.

Os prefixos DOIs são fornecidos às editoras ou metaeditoras pelas agências de registro e iniciam sempre com o algarismo "10", para se diferenciarem de outros sistemas Handle. O algarismo é seguido por um ponto (.) e pelo identificador do registrante (editora ou metaeditora).

As editoras ou metaeditoras são identificadas por quatro ou mais dígitos. Cada prefixo representa um membro da Crossref e pode estar vinculado a uma ou mais revistas. Por isso, um periódico pode ter um prefixo próprio, tendo exclusividade na identificação, ou compartilhar o prefixo entre várias revistas, sendo particularizado no sufixo.

A estrutura do sufixo é mais livre, não possuindo padrão para sua construção. É prática entre algumas editoras inserir o ISSN de revistas ou o ISBN de livros para geração de sufixos únicos. 
Nem todos os caracteres são permitidos na formação do sufixo, como o " $\&$ ", por exemplo. Os caracteres permitidos na criação do nome DOI são:

- Letras minúsculas;

- Letras maiúsculas;

- Traço;

- Ponto;

- Sublinhado;

- Ponto e vírgula;

- Abrir e fechar parênteses;

- Barra.

O sistema DOI não é sensível ao caso, ou seja, não faz distinção entre letras maiúsculas e minúsculas (case-insensitive). Por isso, prefixo/Revista_A e prefixo/revista_a são nomes DOI iguais. Entretanto, em muitos casos, por questões puramente de registros, o sistema DOI não converte os caracteres, mantendo como foi registrado, mesmo que não faça distinção.

Os sufixos podem ser criados de forma a representar informação hierárquica ou níveis de granularidade por meio de nós, ou seja, cada conjunto de caracteres, ou nós, é gerado a partir de uma informação, formando o sufixo, conforme a Figura 7. Assim, por exemplo, o primeiro nó pode representar o título da revista, o segundo nó o fascículo (por meio do ano, volume e número) e, por fim, o terceiro nó representa o artigo.

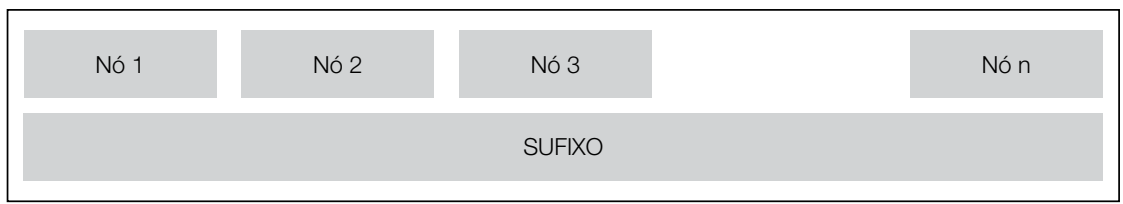

Figura 7 - Uso de representação hierárquica na formação do sufixo em nomes DOI.

\section{Sugestões para nomes DOI}

A norma indica que o nome DOI é opaco, a partir do qual nenhuma informação pode ser deduzida diretamente sem consulta ao sistema de resolução de nomes. Entretanto, é possível gerar nomes DOI que expressem certa semântica, 
de forma sintática, ou seja, cada parte do nome DOI (nó) tem um sentido. Com isso, podem-se gerar nomes que alinhem hierarquia com granularidade, unindo sentido (semântica) e ordem (sintaxe).

A seguir, são apresentadas sugestões para geração de nomes DOI em diferentes casos.

\section{Periódicos e artigos}

Os prefixos podem ser ofertados às revistas de duas formas básicas: pelo editor (um prefixo para cada revista) e pela instituição (metaeditor), compartilhando o prefixo entre revistas. Assim, pode-se particularizar o periódico com um prefixo exclusivo, no caso de um editor publicar apenas uma revista. Em outros casos, como nos portais de periódicos, o metaeditor é o mais comum, e um prefixo será compartilhado por todas as revistas, diferenciando-se cada publicação apenas pelo sufixo.

Quanto ao sufixo, os periódicos geralmente possuem três níveis hierárquicos ou de granularidade: título da revista, suas edições e seus artigos. Com isso, em cada um desses níveis, pode haver regras sugeridas de forma a particularizar cada parte.

Assim, para os títulos das revistas, sugere-se:

- Incluir como primeiro nó em seu sufixo o ISSN, que é um identificador internacionalmente reconhecido e único, com ou sem a palavra ISSN;

- Utilizar a sigla da revista. Porém, isso pode causar problemas, na medida em que mais de uma revista pode ter a mesma sigla ou nome abreviado. Deve-se ficar atento ao caso de a sigla da revista possuir o caractere " $\&$ ", que não é aceito em nomes DOI.

Para os fascículos, pode-se incluir ano, volume e número, de forma a criar um nó exclusivo para cada edição. Assim, por exemplo, 2015vlil refere-se a uma publicação feita em 2015, sendo o volume 1 e o número 1 . Nota-se que cada granularidade deve manter a univocidade do identificador.

Os artigos, por sua vez, devem ser representados por um ou mais nós que os particularizem em uma publicação. Dessa forma, pode-se criar os seguintes tipos de nós:

- Página inicial e final do artigo, caso as revistas insiram paginação;

- Um número sequencial conforme a ordem de publicação. 
Para outros elementos dos periódicos, como editoriais, resenhas e outras modalidades, pode-se seguir a mesma sugestão dos artigos.

Teses e dissertações

As teses e dissertações não são oficialmente publicadas por uma editora e são consideradas literatura cinzenta, embora atualmente sejam amplamente disseminadas. A atribuição de DOI para essa literatura torna-se uma estratégia de valorização, apoio a citação e disseminação. Entretanto, essa atribuição requer alguns procedimentos, visto que a instituição de defesa deve assumir o papel de editora.

A universidade deve ter um prefixo que oferte os nomes DOI para as teses e dissertações defendidas na instituição. Em muitos casos, as universidades se apresentam como metaeditoras, com um prefixo único para todos os periódicos publicados pela instituição. Assim, o prefixo pode ser o mesmo para teses e dissertações, apresentando unificação de prefixos para todos os nomes DOI da instituição.

Quanto ao sufixo, uma sugestão é iniciar pela sigla do programa de pós-graduação, como o primeiro nó, seguido pelo ano de defesa, identificador para o trabalho, seguidos do nó para especificar se é tese ou dissertação.

Por ter de ser unívoco, ou seja, sem a possibilidade de repetições, o nó que identifica a tese ou dissertação revela-se como o maior desafio, na medida em que deve identificar o documento entre outros defendidos no mesmo ano e no mesmo programa de pós-graduação. Números sequenciais podem ser uma opção, mas possuem pouca significância. Usar as iniciais do aluno pode ocorrer em duplicidade. Assim, um conjunto das duas opções pode representar uma solução mais adequada.

Portanto, como apresentado na Figura 8, um exemplo para um nome DOI para teses e dissertações possui um prefixo da instituição ou de algum de seus representantes, como editora universitária, biblioteca etc. O sufixo torna-se uma sequência de nós que identificam univocamente a tese ou dissertação.

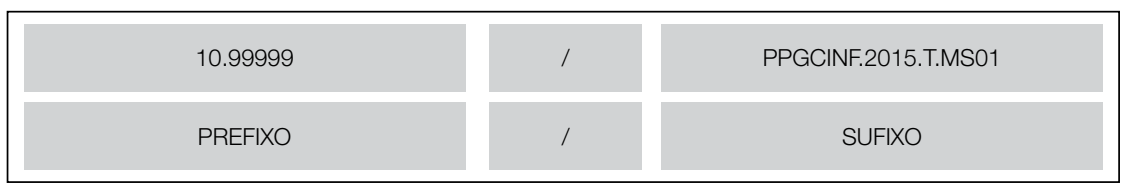

Figura 8 - Proposta de nome DOI para tese ou dissertação. 


\section{Eventos e artigos de eventos}

Eventos indicam certos desafios para a oferta de nomes DOI, principalmente por causa do prefixo, na medida em que não há uma editora, sendo os anais publicados de forma não oficial. Em muitos casos, um evento pode ser promovido por várias instituições, o que dificulta a utilização do prefixo da instituição na estrutura do nome DOI. O ideal é que o evento possua o próprio prefixo, como uma editora de revista, embora isso nem sempre seja possível.

Com relação à oferta do prefixo, os eventos podem ser categorizados em:

- Eventos pertencentes a uma instituição, como associação científica, instituto de pesquisa ou ensino. Nesse caso, a instituição fornece o prefixo como se fosse um editor;

- Eventos em que não há vinculação com uma instituição única. A cada ocorrência do evento, uma instituição se responsabiliza pela promoção. Nesse caso, tem-se as seguintes opções:

- A instituição promotora do evento oferta o prefixo, mas os nomes DOI dos artigos publicados nos anais não possuirão padronização, visto que, em cada ocorrência do evento, os artigos terão prefixos diferentes, o que não é um problema sério, apenas falta de uniformidade;

- O evento adquire o próprio prefixo, o que requer custos para manutenção com anuidade e aquisição dos DOIs para os artigos dos anais. A instituição promotora do evento arca com os custos relacionados à manutenção $\mathrm{e}$ oferta de DOIs em cada ocorrência.

Essas são algumas sugestões para o sufixo dos anais do evento, que possui três níveis de granularidade: o evento em si, os anais e os artigos.

Desse modo, para os eventos:

- Caso o evento possua ISSN, assim como as revistas, esse número pode ser inserido como o primeiro nó;

- A sigla do evento pode representar o primeiro nó. 
Para os anais, pode-se iniciar pela ocorrência do evento, que geralmente é representada por algarismos romanos (I, II, III, ...), e a sigla ou nome abreviado do mesmo, seguido pelo ano. Nota-se que há eventos com mais de uma ocorrência por ano; por isso, somente o ano não é o bastante. Com as duas informações, cria-se uma identificação inequívoca dos anais.

Quanto aos artigos publicados nos anais, pode-se seguir as mesmas indicações dos artigos de periódicos, na medida em que possuem similaridades, pois são artigos diferenciados apenas pelo canal de publicação.

\section{Relatórios técnicos}

Relatórios técnicos são produções institucionais que, até pouco tempo, tinham disseminação restrita, circulando apenas no âmbito da instituição que os produziu. Entretanto, com a Internet, é cada vez mais comum que esse tipo de documentação seja disponibilizado ao público em geral, podendo ser acessado, compartilhado e utilizado por diferentes interessados. Com a atribuição do DOI, os relatórios técnicos passam a ter maior visibilidade. Desse modo, a instituição produtora do relatório técnico deve possuir o prefixo do DOI. Para a geração dos sufixos, pode ser aplicada a identificação interna ou outros elementos, como:

- Projeto (sigla, abreviatura ou nome);

- Ano em que foi produzido;

- Ordem sequencial;

- Sobrenome do autor.

Nas Figuras 9 e 10, são apresentados exemplos de DOIs para relatórios técnicos.

\begin{tabular}{|c|c|c|}
\hline 10.99999 & I & RT.2015.2.Silva \\
\hline PREFIXO & I & SUFIXO \\
\hline
\end{tabular}

Figura 9 - Nome DOI para relatório técnico desenvolvido por Silva em 2015, sendo o segundo do referido ano. 


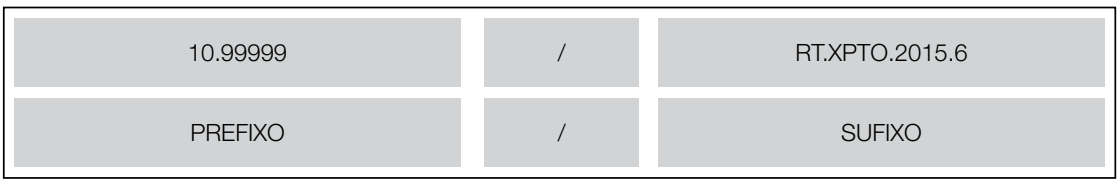

Figura 10 - Nome DOI para relatório técnico do projeto XPTO, realizado em 2015, sendo o sexto do referido ano.

Dessa forma, pode-se criar um sufixo único para os relatórios técnicos, destacando-se que, geralmente, não possuem granularidade. Por isso, tem-se apenas um sufixo do relatório como um todo. Entretanto, pode-se atribuir nomes DOI a diferentes partes do relatório, se necessário, principalmente no caso de essas partes serem referenciadas por documentos externos.

\section{Livros e capítulos de livros}

Livros e capítulos apresentam dois níveis de granularidade. Assim, pode-se ter um DOI para o livro como um todo e um DOI para os capítulos. É possível inclusive atribuir DOI a determinada parte do livro, como uma ilustração ou trecho do texto, com níveis de granularidade menores. Entretanto, o mais comum mesmo é atribuir DOI para livro ou capítulo.

O prefixo deve ser ofertado pela editora do livro. No caso das editoras universitárias, pode-se requerer o mesmo prefixo da universidade, unificando o prefixo para todos os tipos de publicação. Com relação aos livros digitais, em casos muito específicos, pode-se utilizar o prefixo do sistema ou instituição que está divulgando o material.

Quanto ao sufixo, é possível utilizar o ISBN para ambos os casos, sendo o suficiente para livros; porém, essa informação deve ser complementada para o capítulo com o número das páginas, por exemplo, de forma análoga aos artigos de periódicos. Assim, o sufixo do livro pode utilizar apenas o ISBN, e o nome DOI do capítulo, o ISBN e os números das páginas.

Deve-se notar que o DOI do livro em geral é único, independentemente da versão ou republicação, a não ser que tenha sido publicado por mais de um editor (apresentando os prefixos dos editores). Mantém-se o DOI, mesmo para outra versão, a menos que haja muitas modificações (de tradutor, por exemplo) que alterem os metadados. 
A Tabela 3 apresenta resumidamente os exemplos de nomes DOI para documentos diversos.

A Tabela 3 - Exemplos de nomes DOI para documentos diversos.

\begin{tabular}{|c|c|c|c|}
\hline $\begin{array}{l}\text { Tipo de } \\
\text { publicação }\end{array}$ & Granularidade & Sugestão & Observação \\
\hline \multirow{4}{*}{ Periódicos } & Periódico & Prefixo/issn & $\begin{array}{l}\text { O ISSN é um identificador único, que } \\
\text { garante a unicidade do nome DOI. }\end{array}$ \\
\hline & Edição & Prefixo/issn.ano.v.i & $\begin{array}{l}\text { Adiciona-se o ano da publicação, o } \\
\text { volume (v) e o número (i) de forma a } \\
\text { particularizar a edição da revista. }\end{array}$ \\
\hline & Artigo & Prefixo/issn.ano.v.n.i-f & $\begin{array}{l}\text { Adiciona-se a página inicial (i) e final (f) } \\
\text { do artigo. }\end{array}$ \\
\hline & Parte do artigo & $\begin{array}{l}\text { Prefixo/issn.ano.v.n.i- } \\
\text {-f(tipo da parte)p }\end{array}$ & $\begin{array}{l}\text { Adiciona-se o tipo da parte do artigo, } \\
\text { como figura (f), tabela (t), quadro (q) e } \\
\text { a página (p). }\end{array}$ \\
\hline \multirow{4}{*}{ Eventos } & Evento & prefixo/e & $\begin{array}{l}\text { Para o primeiro nó do nome DOI (e): } \\
\text { caso os anais do evento possuam } \\
\text { ISSN, recomenda-se utilizá-lo por ser } \\
\text { um identificador único para publicações } \\
\text { seriadas. Caso não possuam ISSN, } \\
\text { pode-se utilizar a sigla do evento. }\end{array}$ \\
\hline & Ocorrência & prefixo/e.o.a & $\begin{array}{l}\text { O segundo nó pode ser composto pela } \\
\text { ocorrência do evento (o), geralmente } \\
\text { em algarismos romanos (I, II, III, ...), } \\
\text { seguida pela sigla do evento e ano (a). }\end{array}$ \\
\hline & Artigo & prefixo/e.o.a.i-f & $\begin{array}{l}\text { Para particularizar os artigos, pode-se, } \\
\text { como nos artigos dos periódicos, } \\
\text { colocar a data inicial (i) e final (f). }\end{array}$ \\
\hline & Parte do artigo & prefixo/e.o.a.i-f.(t)p & $\begin{array}{l}\text { O mesmo caso para partes de artigo } \\
\text { de revistas. }\end{array}$ \\
\hline \multirow{3}{*}{ Livros } & Livro & prefixo/isbn & $\begin{array}{l}\text { O ISBN é um identificador único } \\
\text { para livro e garante a unicidade do } \\
\text { nome DOI. }\end{array}$ \\
\hline & Capítulo & prefixo/isbn.i-f & $\begin{array}{l}\text { Para o capítulo de um livro, sugere-se } \\
\text { adicionar as páginas iniciais e finais. }\end{array}$ \\
\hline & $\begin{array}{l}\text { Parte do } \\
\text { capítulo }\end{array}$ & prefixo/isbn.i-f.(t)p & $\begin{array}{l}\text { Para partes do livro como gravuras, } \\
\text { quadros e tabelas, pode-se acrescentar } \\
\text { o tipo da parte e a página onde ocorre. }\end{array}$ \\
\hline $\begin{array}{l}\text { Relatórios } \\
\text { técnicos }\end{array}$ & Nenhuma & $\begin{array}{l}\text { prefixo/identificador } \\
\text { interno }\end{array}$ & $\begin{array}{l}\text { É possível utilizar também o ano e o } \\
\text { número sequencial. }\end{array}$ \\
\hline $\begin{array}{l}\text { Tese e } \\
\text { dissertação }\end{array}$ & Nenhuma & $\begin{array}{l}\text { prefixo/sigla do } \\
\text { programa.data.nome } \\
\text { do aluno }\end{array}$ & $\begin{array}{l}\text { O sufixo pode se basear também em } \\
\text { dados do título do trabalho, separados } \\
\text { por pontos. }\end{array}$ \\
\hline
\end{tabular}




\section{Como indicar o DOI nas referências}

Ao se questionar sobre a finalidade das referências em um documento, pode-se afirmar que estas são imprescindíveis para que o leitor localize de forma inequívoca as fontes citadas pelos autores do documento. As normas de referências existem para que os autores não omitam nenhum elemento importante utilizado na identificação do documento citado. Posto isso e considerando-se as possibilidades dos documentos digitais - impensáveis para os impressos - , sem esquecer que as normas, em geral, se adaptam às mesmas regras dos impressos, sugerimos uma reflexão a respeito do futuro das referências.

Quando o uso dos indicadores persistentes for massivo, tanto de DOIs para os documentos quanto de ORCIDs para os autores, provavelmente as normas de referência precisarão se adequar. Um documento poderá ser referenciado unicamente pelo nome DOI, o qual conterá em seus metadados os identificadores dos autores. No entanto, enquanto as normas não contemplarem as novas funcionalidades possíveis, especialmente para documentos digitais, precisaremos fazer as adequações necessárias.

Nas referências, o ideal é que o nome DOI do documento referenciado forneça o link ativo e completo, ou seja, sempre precedido de http://dx.doi.org/. Desse modo, o leitor já terá acesso ao texto completo em um único clique. Indicar apenas DOI: 10.5007/1518-2924.2015v20n42p79 na referência não levará o leitor a lugar algum. Por definição, o DOI é um localizador, um resolver; assim, se não oferecer acesso imediato em um clique ao texto completo, não se apresenta como localizador. Entretanto, ainda há editores que insistem em não indicar a URL do DOI completa e hiperlinkada.

Outra justificativa importante para que se indique o DOI hiperlinkado em todas as referências é a facilitação para que as métricas de acesso e citação sejam aplicáveis sem grandes problemas. Somente o código DOI, por não ser uma URL, não servirá de ponto de acesso para indexadores automáticos.

Portanto, os editores deverão informar, nas diretrizes aos autores de suas revistas, o padrão para indicação do DOI nas referências dos artigos. Há 
algumas formas, sendo as mais recomendadas e comumente utilizadas apresentadas a seguir:

Opção 1: Usar um DOI com link permanente, sem indicar a URL do artigo na revista

Neste exemplo, o DOI é colocado no final da referência, sem necessidade de indicar "Disponível em/Acesso em", caso a norma adotada seja a ABNT. Essas informações só têm sentido em documentos publicados na web sem DOI, indicando que, naquela data, a URL estava disponível. Com o DOI, são redundantes, totalmente desnecessárias.

FELISBERTO, Proxério Manoel; MARCELINO, Roderval; ALVES, Maria Bernardete Martins; ALVES, João Bosco da Mota; SILVA, Juarez Bento da; GRUBER, Vilson. A geração e o gerenciamento de referências bibliográficas com o Mecanismo Online para Referências - MORE. Encontros Bibli: Revista Eletrônica de Biblioteconomia e Ciência da Informação, Florianópolis, v. 20, n. 42, p. 79-92, abr. 2015. http://dx.doi.org/10.5007/1518-2924.2015v20n42p79

Nota-se que não há necessidade de indicar a URL da revista. Se for indicado somente o DOI, todas as métricas de acesso e citação ficarão concentradas em um só lugar, ou seja, no DOI. Portanto, não é recomendável indicar, na referência, o DOI juntamente com a URL da revista, para que as métricas não se dispersem por duas URLs do mesmo artigo.

Opção 2: Substituir o nome DOI pela logomarca hiperlinkada da Crossref

Esta opção deverá ser a preferida se, após a referência, estejam indicadas outras bases indexadoras, como, por exemplo, Scopus, PubMed etc.

FELISBERTO, Proxério Manoel; MARCELINO, Roderval; ALVES, Maria Bernardete Martins; ALVES, João Bosco da Mota; SILVA, Juarez Bento da; Gruber, Vilson. A geração e o gerenciamento de referências bibliográficas com o Mecanismo Online para Referências - MORE. Encontros Bibli: Revista Eletrônica de Biblioteconomia e Ciência da Informação, Florianópolis, v. 20, n. 42, p. 79-92, abr. 2015. Crossre!

Opção 3: Usar um encurtador de links (ShortDOI) no final da referência

O serviço ShortDOI é um sistema aberto que cria atalhos para nomes DOI, gerando ligações permanentes bem curtas, e isso pode ser importante em situações nas quais o espaço é limitado. 
FELISBERTO, Proxério Manoel; MARCELINO, Roderval; ALVES, Maria Bernardete Martins; ALVES, João Bosco da Mota; SILVA, Juarez Bento da; Gruber, Vilson. A geração e o gerenciamento de referências bibliográficas com o Mecanismo Online para Referências - MORE. Encontros Bibli: Revista Eletrônica de Biblioteconomia e Ciência da Informação, Florianópolis, v. 20, n. 42, p. 79-92, abr. 2015. http://doi.org/6tz

Entretanto, deve-se ponderar se vale a pena sua utilização, pois as métricas serão contabilizadas por URL. Portanto, o ShortDOI poderá roubar citações e acessos do DOI completo, já que as métricas utilizam contadores automáticos que não fazem a diferenciação entre ShortDOI e DOI completo. Para maiores informações sobre como utilizar esse serviço, consulte o ShortDOI Service.

Outros exemplos podem ser conferidos no portal da Crossref ${ }^{8}$. 


\section{DEPÓSITO DE METADADOS NO SISTEMA DOI}

Os nomes DOI são gerados pelos editores e atribuídos aos objetos. Após esse processo, é preciso depositar os metadados associados a esses objetos em uma agência de registro para que os nomes DOI se tornem válidos. Somente depois desse processo, o nome DOI estará totalmente operacional.

Após a validação e o processamento desse depósito, os nomes passam a constar no sistema DOI, sendo então possível a recuperação de seus metadados, o que permite o acionamento de diferentes serviços. Recomenda-se que a publicação do nome DOI na página dos artigos/teses ou demais objetos seja realizada somente após esse processamento, ou seja, quando já estão clicáveis e direcionam a um endereço válido.

No contexto da agência de registro Crossref e do sistema Open Journal Systems (OJS), existem duas formas principais de registro dos metadados: o depósito via formulário web e o depósito automático via plug-in de exportação de dados do OJS. A seguir, são apresentados esses dois métodos de registro.

\section{REGISTRO VIA FORMULÁRIO WEB}

A Crossref oferece um formulário web para registro de metadados associados aos nomes DOI, o qual é apresentado na Figura 11.

Nesse formulário, primeiramente, o editor indica para qual tipo de publicação será ofertado o DOI - artigo, livro, anais de conferência, relatório, tese/dissertação, informação sobre direitos autorais ou de agências de financiamento (Supplemental-Metadata). Para tanto, basta clicar na opção desejada, na parte superior do formulário. Após informar os valores dos respectivos campos, o registrante informa seu nome de usuário e senha, completando o depósito de metadados. 


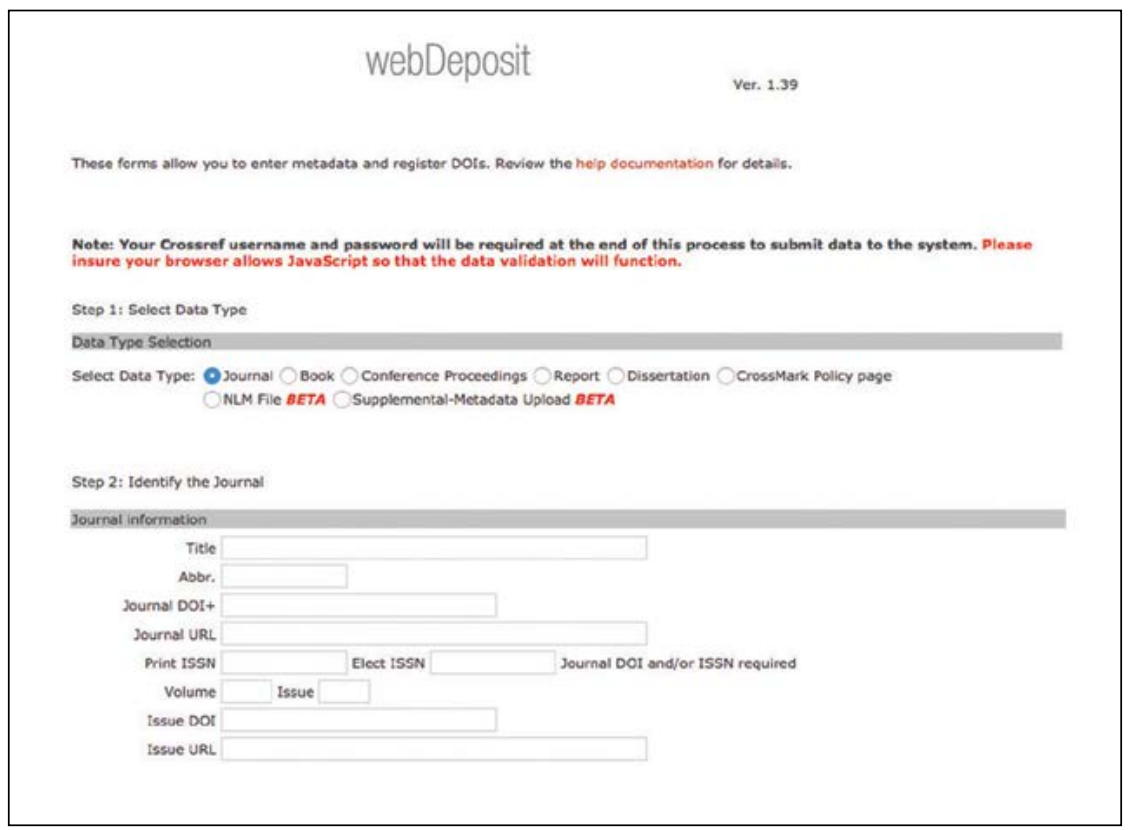

Figura 11 - Formulário web para depósito de metadados ${ }^{9}$.

Essa abordagem para o depósito de metadados é indicada em situações nas quais os sistemas utilizados na publicação dos documentos não oferecem meios automáticos para depósito de metadados. É um procedimento repetitivo e sujeito a erros gerados pelo usuário, como os decorrentes de digitação com troca de caracteres, por exemplo.

\section{REGISTRO VIA OPEN JOURNAL SYSTEMS}

O sistema para editoração de revistas em meio digital OJS, sistema utilizado na editoração de revistas científicas em meio digital, que, no Brasil, também é conhecido como Sistema de Editoração Eletrônica de Revistas (SEER). em sua versão 2.4.7, oferece recursos para atribuição de DOI em suas edições e artigos, bem como o depósito automático de metadados junto à agência de registro Crossref.

De forma geral, o procedimento consiste em: 
- Habilitar o plug-in de identificação pública;

- Configurar o plug-in quanto ao padrão de geração de nomes DOI e tipos de objetos a serem identificados;

- Configurar o plug-in quanto aos dados de acesso ao sistema de depósito;

- Registrar os nomes DOI, validando e corrigindo os metadados quando necessário.

Dessa forma, o passo inicial para o uso do plug-in é habilitá-lo. Isso é feito pelo editor-gerente da revista em "Plugins do Sistema" > "Plugins de identificação pública", conforme Figuras 12 e 13.

Capa > Usuário > Administraçăo

\section{Administração}

\section{Configurações e ferramentas}

* Naveqador de Arquivos

- Seçōes

- Formulários de avaliação

^Idiomas

- Expediente

* E-mails

- Ferramentas para Leitura

- Confiquracão

- Estatísticas \& Relatórios

^ Formas de pagamento

- Pluqins do Sistema

- Importar/Exportar dados

\section{Usuários}

* Usuários cadastrados nesta revista

- Cadastrar usuário do portal nesta revista

- Exibir usuários sem papéis

- Incluir novo usuário

- Mesclar cadastros

Figura 12 - Acesso ao plug-in para atribuição de DOI. 
Capa > Usuário > Administração > Administração de Plugins

\section{Administração de Plugins}

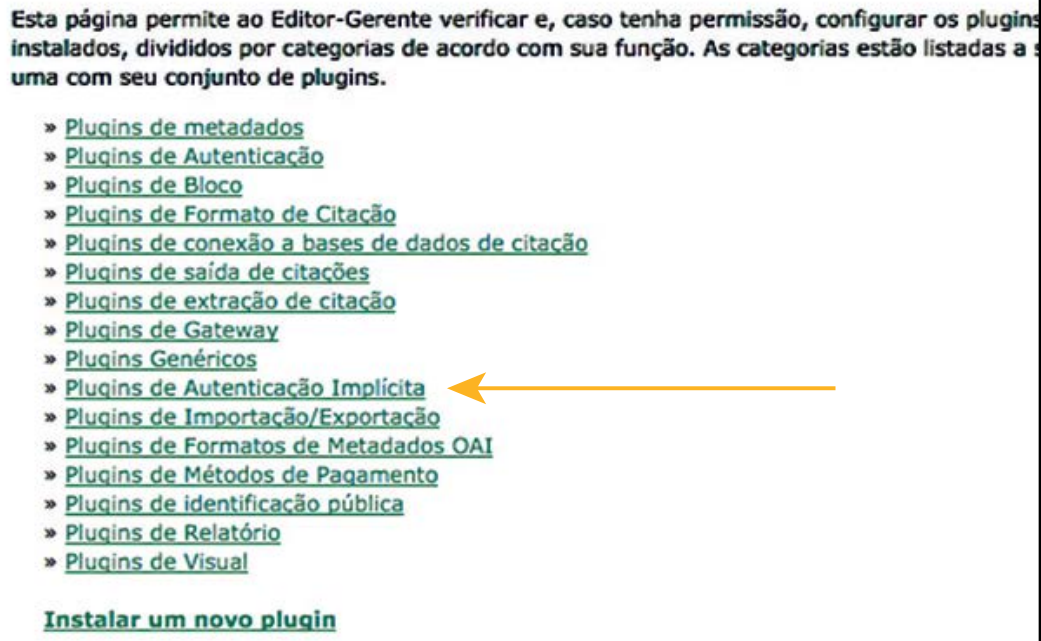
instalados, divididos por categorias de acordo com sua função. As categorias estäo listadas a uma com seu conjunto de plugins.

- Pluains de metadados

- Pluqins de Autenticacão

- Plugins de Bloco

- Pluains de Formato de Citacão

- Pluqins de conexão a bases de dados de citacão

- Pluains de saida de citacões

* Pluqins de extracão de citacão

- Pluqins de Gateway

- Pluains Genéricos

- Pluqins de Autenticacão Implicita

- Pluains de Importacão/Exportacão

- Pluains de Formatos de Metadados OAI

- Pluains de Métodos de Pagamento

- Pluains de identificacão pública

- Pluqins de Relatório

- Pluains de Visual

Instalar um novo pluqin

Figura 13 - Acesso ao plug-in para atribuição de DOI.

Após habilitado, o plug-in deve ser configurado, existindo dois elementos principais a serem definidos: o padrão de geração de nomes DOI e quais objetos terão identificador; e os dados de acesso ao sistema de depósitos da agência de registro.

Para configurar o padrão de geração de nomes DOI, o editor-gerente deve acessar as configurações do plug-in no mesmo caminho utilizado para sua habilitação. Uma vez na tela de configurações, é possível escolher quais os objetos que receberão identificadores; no caso, a Crossref recomenda apenas atribuir a Edições e Artigos. Conforme a Figura 14, é também nessa tela que o editor-gerente define o padrão de geração de nomes. 
Capa > Usuário > Editor-Gerente > Plugins do Sistema > Configuraçōes

\section{Configurações}

Configure o plugin DOI para gerenciar e usar DOIs no OJS:

Conteúdo * Escolha os objetos publicados que terão Identificadores de Objeto Digital (DOI) atribuidos:

NOTA: Ao usar DOIs do CrossRef, é necessário escolher artigos. Artigos são vistos como trabalho, isto é, entidade de conteúdo intelectual e artístico. Logo, artigo é o objeto de publicação no qual está baseados exportação e registro do DOI CrossRef..

Edições

Artigos

Composiçōes

Arquivos suplementares

Prefixo DOI * O prefixo DOI é atribuido por agèncias de registro (ex.: CrossRef) e possui o formato 10.xxxx (ex.: 10.1234):

$\longdiv { 1 0 . 1 7 5 6 3 }$

Sufixo DOI O sufixo DOI pode assumir qualquer forma, desde que seja único entre todos todos os objetos publicados com o mesmo prefixo DOI:

Use o padrão informado a seguir para gerar sufixos DOI. Use \%j para iniciais da publicação, \%v para o volume, \%i a ediçăo, \%Y para o ano, \%a para o ID do artigo OJS, \%g para o 10 da composição OJS, \%s para o ID do arquivo suplementar ojS e \%p para o número da página.

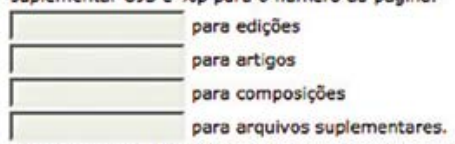

Por examplo, vol\%viss\%ipp\%p poderiam criar um DOI com estrutura $10.1234 / \mathrm{vol} 3$ iss2pp230

Figura 14 - Tela de configuração do padrão de geração de nome DOI.

Pode-se notar, ao final do formulário, o botão "Atribuir DOls novamente". Esse botão deve ser utilizado quando ocorre mudança no padrão de geração de nomes DOI, para que os nomes sejam atualizados. Porém, é importante notar que, caso já tenham sido depositados metadados referentes a nomes previamente gerados, o botão jamais deverá ser acionado, pois não se pode atribuir nomes DOI diferentes para os mesmos objetos, causando o chamado "conflito de nome DOI", o que gera penalidades e deve ser solucionado. Para mais informações, ver o tópico correspondente na seção sobre "Problemas comuns".

Uma vez configurado o esquema de geração de nomes e definidos os objetos que receberão identificadores, o plug-in fará com que o OJS exiba os nomes DOI de artigos e edições publicadas, conforme a Figura 15. Entretanto, esses nomes ainda não são válidos no sistema DOI. Para isso, é necessário o seu depósito na agência de registro, no caso, a Crossref. 


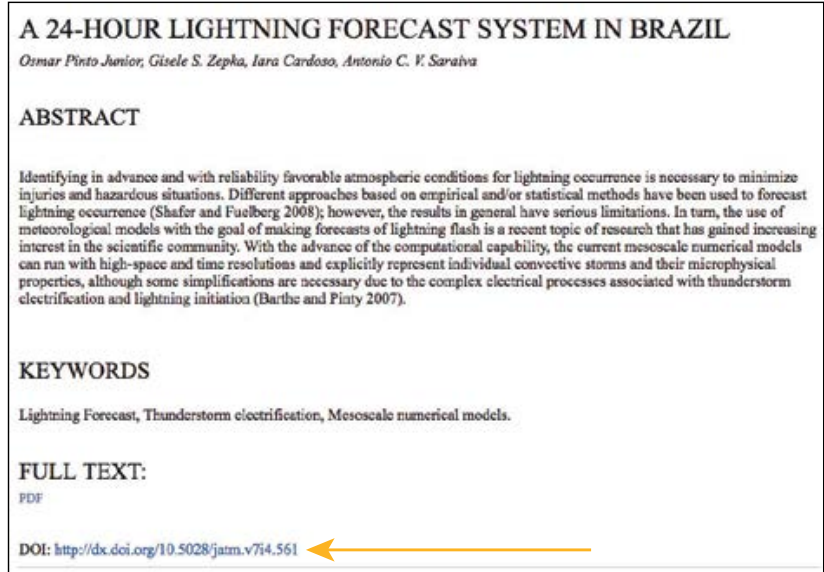

Figura 15 - Revista em OJS exibindo o nome DOI em um resumo ${ }^{10}$.

O próximo passo é configurar os dados de acesso ao sistema de depósito dos metadados. Para isso, o editor-gerente deve acessar, a partir de sua página de usuário, a opção "Importar/Exportar dados > Exportação Crossref em XML”, conforme a Figura 16.

Capa > Usuário > Administraç̄o > Importar/Exportar dados

\section{Importar/Exportar dados}

Importaç̃o/Exportaclo DuraCloud: Arauiva e restaura ediçōes usando um serviço de armazenamento externo Duracloud

- Pluain de identificadores súblicos em XML: Importa e exporta identificadores públicos

- Exportacìo para formato Erudit: Exporta artigos utilizando a DTD inglesa Erudit

- Exportacjo formato METS XML: Exportar revistas no formato METS XML

- Usuárices em XML: Importar e exportar cadastros no formato XML

- Expertaclo formato PubMed XML: Exporta metadados de artigos no formato PubMed XML para indexaçäo na MEDLINE.

- Exportaclo/Recistro Datacite: Exporte ou registre metadados de ediç̄es, artigos, composiç̄es e arculvos suplementares no DataCite.

- Exportaclo CrossRef em XML: Exporta metadados dos artigos no formato CrossRef XML.

- XML de artigos e ediç̃es: Permite importar e exportar artigos e ediçỗes em XML.

- Exportacio para DOAJ: Exportar revista para o DON, induinco dados da revista para inclusajo.

- Plugin de Exportacbio/Registro mEDRA: Exporta metadados de ediç̄es, artigos e composiç̄es finais no

formato Onix para DOI (OADON) e registra DOIs na agéncia de registro mEDRA.

- Submisstio rópida: Plugin de submissbio em 1 passo

Figura 16 - Acesso ao plug-in para exportação de metadados do DOI.

De fato, essa é a página utilizada para a exportação dos metadados dos artigos e edições, bem como para o respectivo depósito na Crossref. Ao mesmo tempo, é a página para se chegar ao formulário de configurações dos dados de acesso. Para defini-los, clique em "configurar o plug-in de exportação/registro Crossref aqui", conforme indicado na Figura 17.

10.http://umw.jatm.com.br/ojs/index.php/jatm/article/view/561 


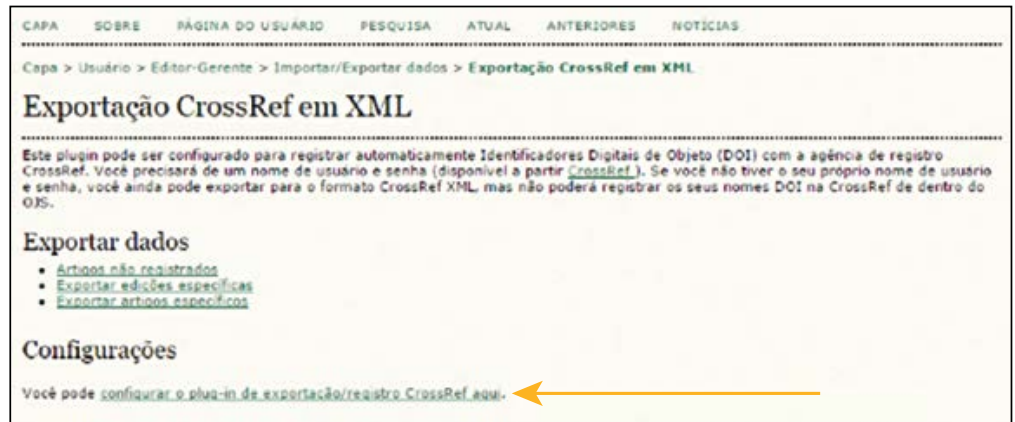

Figura 17 - Acesso ao formulário de configuração de dados de acesso à Crossref.

Ao clicar no link indicado, o editor-gerente será levado ao formulário (Figura 18) onde deve informar, nos respectivos campos, o nome de usuário e senha recebidos da ABEC. Em nome e e-mail do depositante, também devem ser informados os dados utilizados na assinatura de representação/filiação à Crossref.

\begin{tabular}{|c|c|}
\hline soske & DESQUISA ATUAL ANTERBORES Noticus \\
\hline \multicolumn{2}{|c|}{ 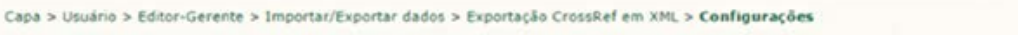 } \\
\hline \multicolumn{2}{|l|}{ Configurações } \\
\hline \multicolumn{2}{|c|}{ 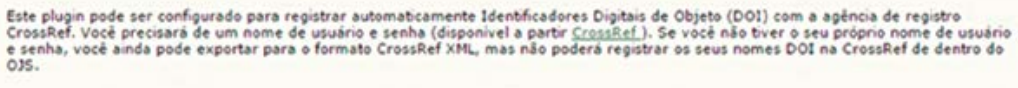 } \\
\hline \multicolumn{2}{|l|}{ Requisitos } \\
\hline \multicolumn{2}{|c|}{ Todos os requistos do plugin est 50 atendidos. } \\
\hline \multicolumn{2}{|l|}{ Configurações } \\
\hline \multicolumn{2}{|c|}{ Os seouintes items sho exigidos para um depdsito bem sucedido no Crossref. } \\
\hline Nome do depositante " & ABEC \\
\hline Email do depositante " & kontato Grevista.org.br \\
\hline \multicolumn{2}{|c|}{ 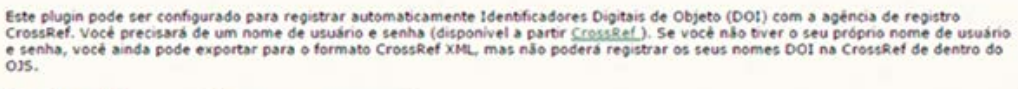 } \\
\hline Nome de usubino & pifro \\
\hline Sento & $\overline{\text { As senhas serbà salvas em texto náo cifrodo. }}$ \\
\hline $\begin{array}{l}\text { Regintrar DOIs } \\
\text { automabcamente }\end{array}$ & 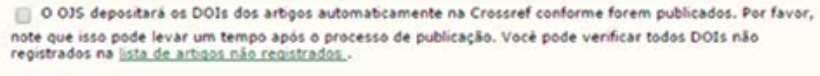 \\
\hline \multicolumn{2}{|l|}{ - indica campo etringationo } \\
\hline Solver Canselor & \\
\hline
\end{tabular}

Figura 18 - Configuração de dados de acesso para depósito automático na agência Crossref. 
Nesse formulário, é possível assinalar uma opção para que o sistema deposite automaticamente os metadados de edições logo após a publicação. Dessa forma, os passos seguintes não são necessários, pois os metadados são enviados no momento da publicação da edição. Entretanto, não se recomenda, em um momento inicial, esse depósito automático, pois diferentes problemas podem impedir seu processamento, devido à relativa imaturidade dos recursos de integração OJS e Crossref (versão 2.4.7).

Portanto, caso a opção de depósito automático não tenha sido habilitada, e após os dados de acesso terem sido configurados, o editor-gerente pode iniciar o registro/depósito dos metadados. Isso é feito a partir da tela apresentada anteriormente, acessada em Importar/Exportar dados > Exportação Crossref em XML.

A partir dessa tela, é possível listar os artigos ainda não registrados, exportar edições ou artigos específicos. Para efetivar o depósito, basta acessar uma dessas opções, selecionar os itens que se deseja registrar e clicar no botão Registrar, conforme indicado na Figura 19.

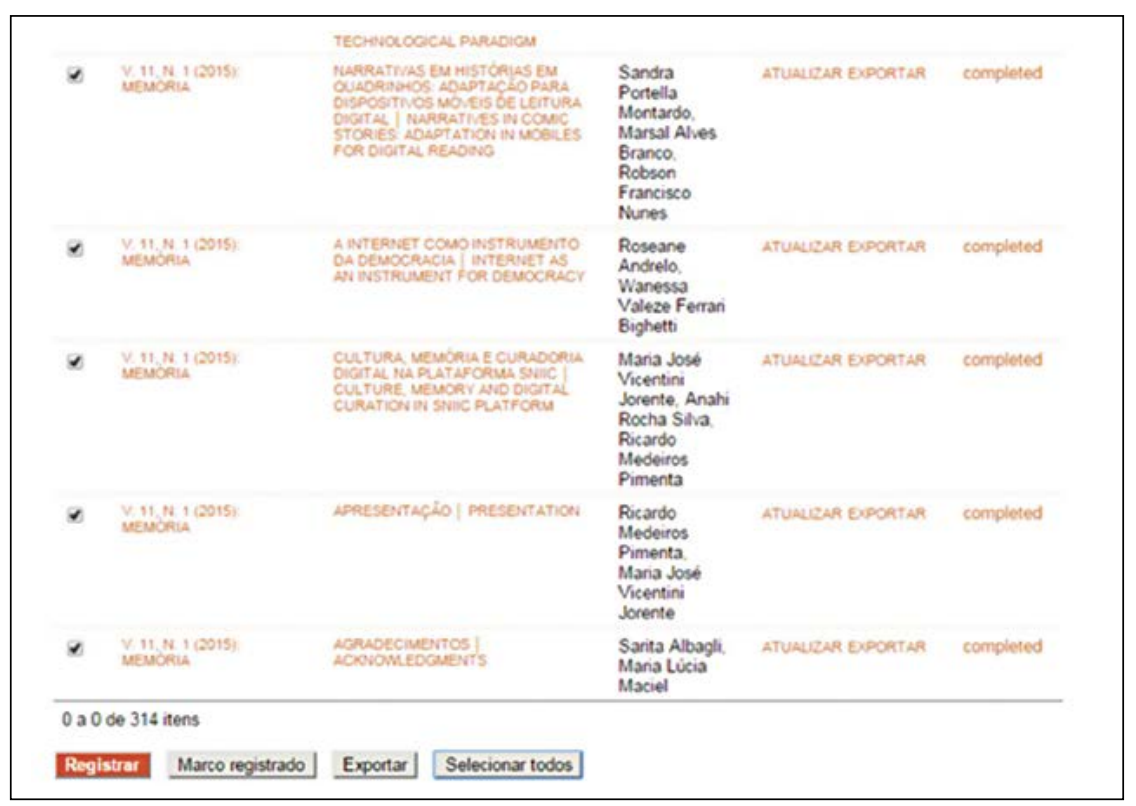

Figura 19 - Lista de artigos que terão seus nomes DOI e respectivos metadados registrados ${ }^{11}$.

11. LINC em Revista 
Ao clicar em Registrar, eventualmente, uma mensagem de erro poderá aparecer no canto superior dessa tela, conforme a Figura 20, impedindo o depósito do item em questão e também dos itens associados ao mesmo. Por exemplo, caso haja erro em um artigo de uma edição, a edição no todo não poderá ser registrada.

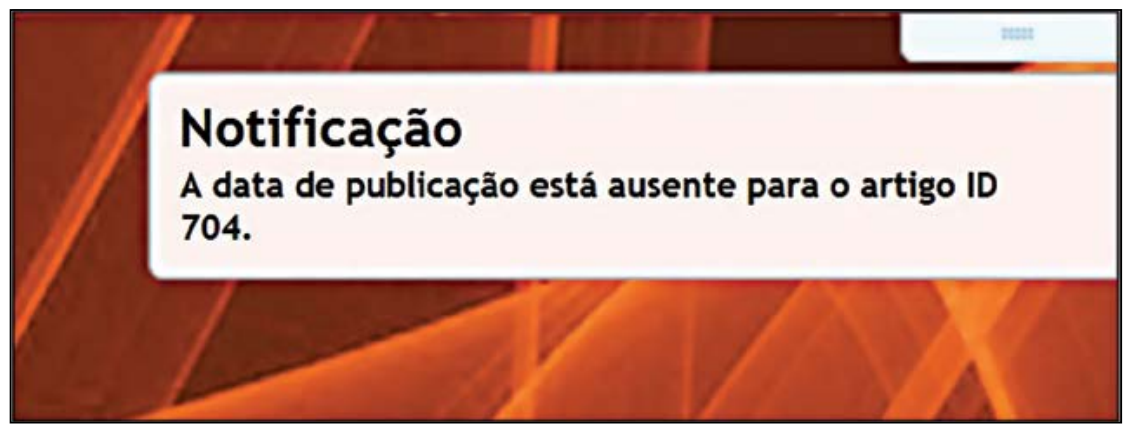

Figura 20 - Erro identificado no momento do registro dos metadados.

Para solucionar casos desse tipo, consulte o tópico "Problemas comuns" deste Guia.

Eventualmente, o registro não funcionará adequadamente, devido a erros ou problemas de conectividade entre o servidor web onde está hospedada a sua revista e o sistema de depósito da Crossref. Caso isso aconteça, recomenda-se o uso do recurso de exportação em vez do registro. Dessa forma, o OJS apresentará um arquivo XML a ser salvo no computador local e enviado manualmente para o sistema de depósito, conforme descrito no próximo tópico.

\section{REGISTRO VIA SISTEMA DA CROSSREF}

Pode ser mais eficaz registrar os nomes DOI diretamente no sistema da agência de registro por meio de arquivo XML. Nesse caso, os metadados são exportados do OJS em um arquivo XML, e o depósito é feito diretamente por meio do sistema da Crossref, conforme apresentado na Figura 21. 


\section{Crossref}

Welcome to CrossRef.

Home Users Submissions Queries Reports

Please supply a login and a password:

login:

space

password:

submit

2000-2016 PILA, Inc.

Figura 21 - Acesso direto ao sistema de depósito da Crossref ${ }^{12}$.

O primeiro passo é acessar o sistema e uma vez realizada sua autenticação, o usuário deve clicar na guia "Submissions", a qual contém o formulário para envio do arquivo XML exportado do OJS, conforme a Figura 22.

Para exportar os metadados em um arquivo XML, basta clicar no botão "Exportar" em vez de "Registrar" na tela de registro de metadados, conforme ilustrado anteriormente na Figura 19.

12.https://doi.crossref.org/servlet/useragent?func=showHome 


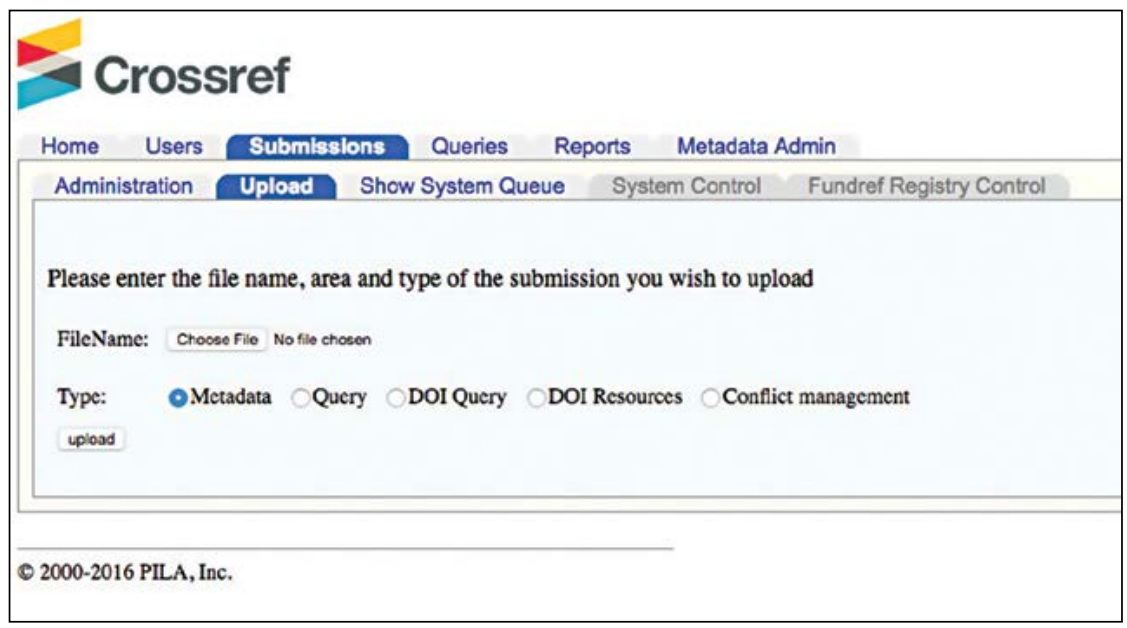

Figura 22 - Formulário para envio de arquivo XML com metadados.

Após selecionar o arquivo e enviá-lo, é apresentada a tela de confirmação de envio (Figura 23), a qual oferece um link para a fila de submissões, que listará todos os envios que estão sendo processados pelo sistema da Crossref para incorporação ao sistema DOI. Nesse processamento, os registros são validados; eventuais erros poderão impedir o depósito de metadados e os nomes DOI associados aos mesmos permanecerão inválidos. Desse modo, é importante realizar o acompanhamento do depósito, descrito no tópico seguinte.

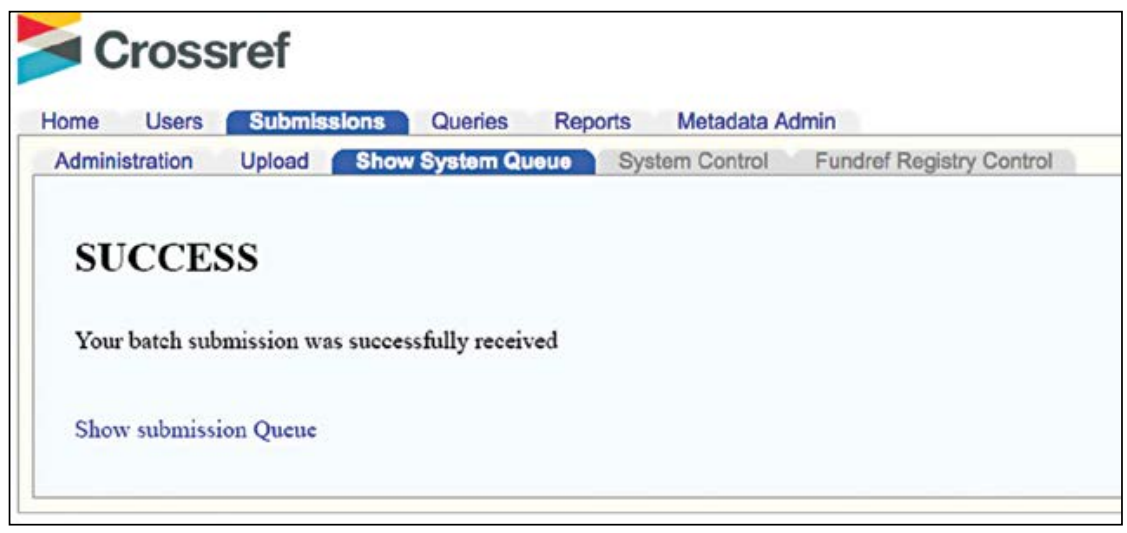

Figura 23 - Confirmação de envio de metadados. 


\section{ACOMPANHAMENTO DO DEPÓSITO}

Após os metadados terem sido depositados, recomenda-se acompanhar seu processamento, pois o sistema DOI não publica de imediato os novos nomes, sendo necessária sua validação e processamento para que sejam disponibilizados para consulta.

Eventualmente, erros não identificados no momento do registro via OJS afetam o processamento do arquivo de metadados, impedindo o registro dos nomes DOI. Esses erros podem ser acompanhados somente via sistema de depósito apresentado aqui.

Desta forma, o processamento do registro pode ser acompanhado por meio do sistema da Crossref, apresentado na Figura 24.

Para acompanhar o processamento dos depósitos, após entrar no sistema com os dados de acesso, deve-se clicar no link "Submission administration", conforme ilustrado na Figura 24.

\section{$\$$ Crossref}

Welcome space

Home Users Submissions Queries Reports Metadata Admin

- Logout

\section{Submission}

- Submission administration

- Upload submissions

- Show my submission queue

2000-2016 PILA, Inc.

Figura 24 - Sistema de depósito e acompanhamento da Crossref. 
Se o OJS não registrar automaticamente os metadados, é por essa interface que deve ser enviado o arquivo XML, no caso, por meio do link Upload Submissions, apresentado na Figura 25.

O link Submission administration levará a um formulário, apresentado na Figura 25, onde podem ser aplicados diferentes filtros, referentes, por exemplo, às datas de envio do depósito, ao término de processamento ou à existência de erros ou conflitos.

\section{Crossref}

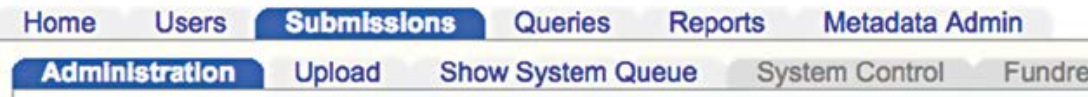

For faster results it is best to supply both a start and an end date, not just one of them. or you can leave both blank.

Submission ID:

Received Date (start):

Received Date (end):

Started Date (start):

Started Date (end):

Finished Date (start):

Finished Date (end):

Registrant:

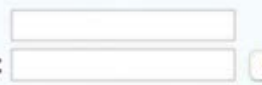

Calendar

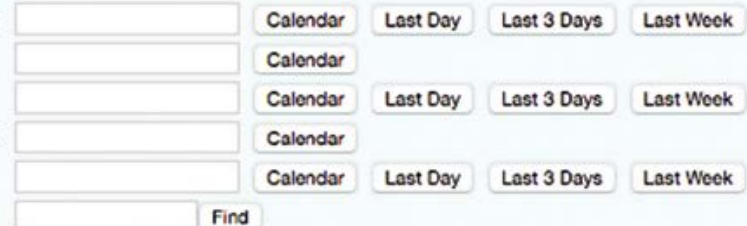

Type:

Al Typos -

Has Error:

Has Conflict:

Soarch Resot

2000-2016 PILA, Inc.

Figura 25 - Formulário para aplicação de filtros e geração do relatório de acompanhamento de depósitos. 
Se necessário, são aplicados os filtros adequados para a busca que está sendo realizada. Nesse caso, vale notar a importância da opção Has Error, a qual trará uma lista de envios de metadados que apresentaram erros, conforme a Figura 26, os quais devem ser tratados para que os nomes DOI se tornem válidos.

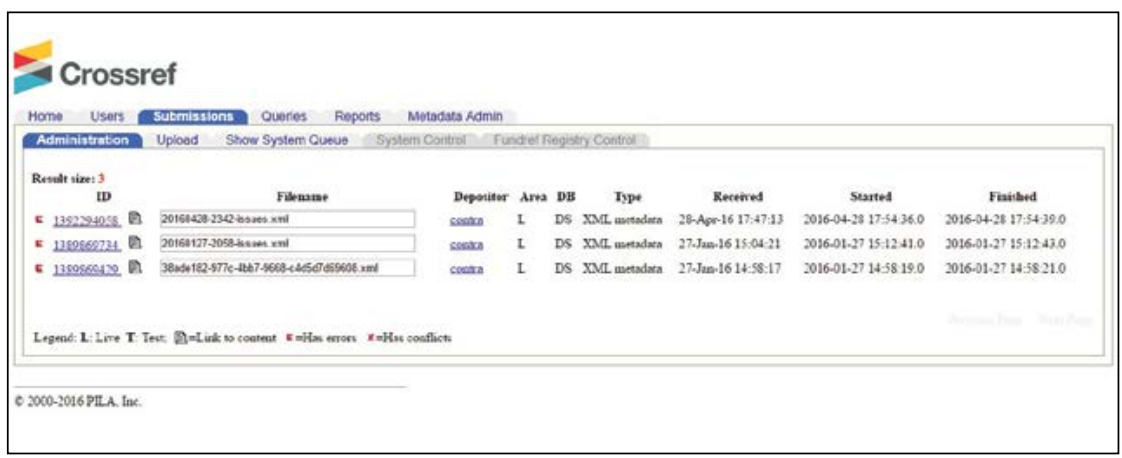

Figura 26 - Lista de submissões com erros gerada a partir dos filtros estabelecidos na etapa anterior.

Após submeter a busca ao sistema, nota-se que a lista de resultados na tela seguinte mostrará o ícone $\mathbf{E}$ em envios que possuem erros. Outras indicações podem ser apresentadas, conforme a legenda do sistema. Para verificar qual o tipo de erro, basta clicar sobre o link correspondente ao ID do depósito. Isso levará a uma tela com as especificações da submissão, apresentada na Figura 27, onde o campo "Message" apresenta detalhes sobre o erro. As mensagens de erro não são as mais amigáveis ao usuário, sendo descritas em formato XML. Para seu entendimento e solução, o usuário deve consultar o tópico sobre mensagens de erro na ajuda da Crossref.

Deve-se lembrar: mesmo que o OJS tenha validado sintaticamente os dados em XML exportados, é possível que o sistema apresente erros decorrentes de outros dados, como, por exemplo, no caso em que o ISSN do depositante já está associado a outro prefixo. 


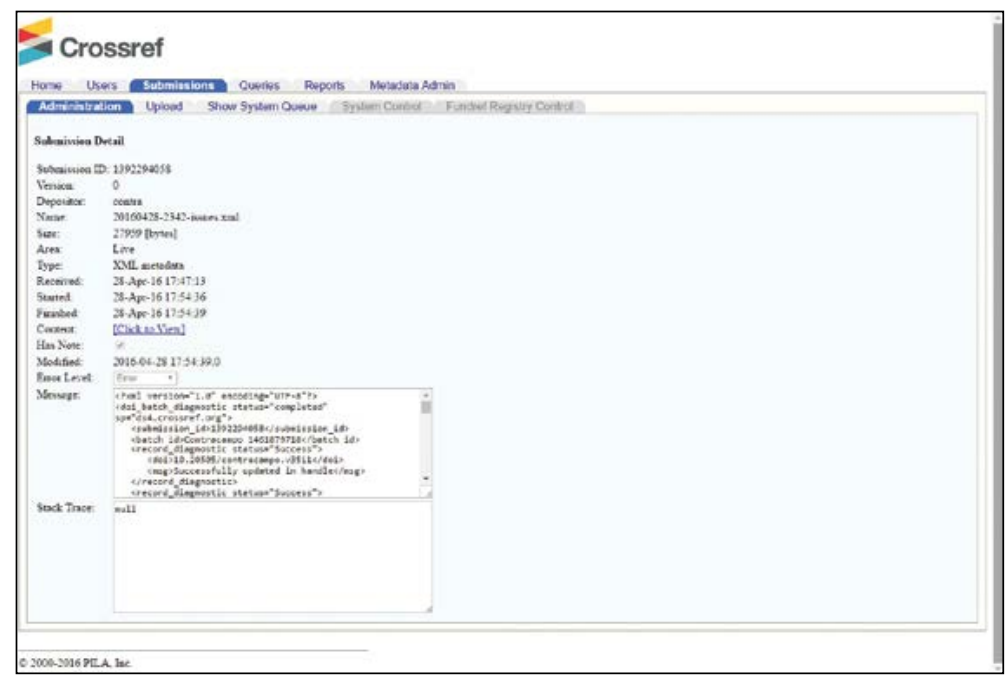

Figura 27 - Tela de acompanhamento da submissão/depósito com mensagem de erro.

\section{ATUALIZAÇÃO DE METADADOS}

Um fator crítico no uso de DOI é a manutenção dos metadados sempre atualizados. Quando nos referimos à manutenção, o elemento chave é a sua localização na web, ou seja, sua URL. Esse elemento de metadado permite que o usuário seja direcionado para a página do artigo após buscar o nome DOI no serviço de resolução de nomes.

A atualização dos metadados deve ser feita principalmente em caso de mudança de nome do servidor, por exemplo, quando uma revista migra de uma instalação própria para um portal institucional ou quando o próprio endereço do portal muda.

Para manter a URL atualizada, assim que o portal de revistas estiver on-line no novo endereço, os editores-gerentes de todas as revistas devem acessar os recursos de exportação/registro DOI e enviar novamente os metadados. Esse procedimento de atualização não gera custos adicionais à revista e é obrigatório, visto que, se não for realizado, o nome DOI passa a ser inválido, pois leva a uma localização inexiste. 


\section{O ARQUIVO XML}

$\mathrm{O}$ arquivo para depósito tem formato XML e é composto por três partes: a declaração inicial, um cabeçalho e o corpo descritivo. Cada parte traz informações específicas que ajudam no processamento desse arquivo, com vistas a validar os DOIs atribuídos e o armazenamento nos bancos de dados da Crossref.

A declaração inicial informa a versão do XML, a codificação do arquivo e seu namespace. Essa informação é importante, pois indica como esse arquivo deve ser processado e validado, apresentando qual deve ser o esquema que verifica sua estrutura. Seu formato é:

$<$ ?xml version="1.0" encoding="UTF-8"?>

<doi_batch xmlns="http://www.crossref.org/schema/4.3.0" xmlns:xsi="http://www.w3.org/2001/

XMLSchema-instance" version="4.3.0" xsi:schemaLocation="http://www.crossref.org/schema/4.3.0

http://www.crossref.org/schema/deposit/crossref4.3.0.xsd">

Já o cabeçalho apresenta informações sobre o arquivo de depósito, identificando o arquivo, já que uma editora enviará vários arquivos para processamento, pois periodicamente deve ofertar DOIs aos artigos publicados. Sua forma é:

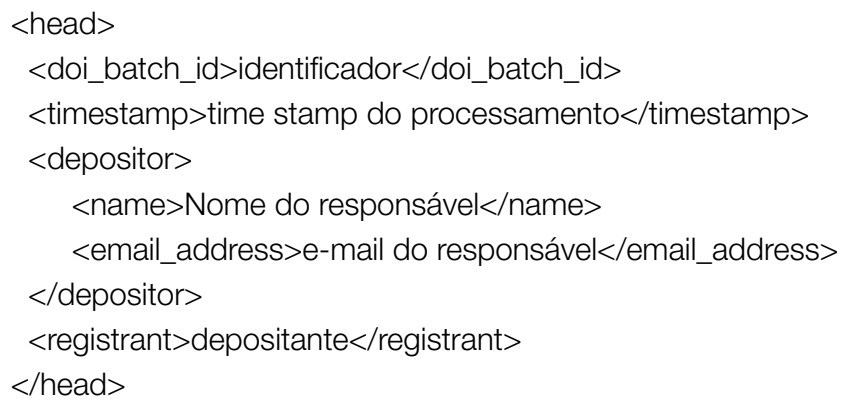

O corpo do arquivo, por sua vez, contém as informações em três blocos: sobre a revista <jornal_metadata $>$, sobre a sua edição <jornal_issue $>$ e sobre os artigos $<$ jornal_article $>$. Seu formato é:

$<$ body $>$

$<$ journal>

$<$ jornal_metadata $>$ 
Informações sobre a revista

$<$ /jornal_metadata>

$<$ journal_issue>

Informações sobre a edição da revista

$<$ journal_issue $>$

$<$ journal_article>

Informação sobre o artigo

$</$ journal article $>$

$<$ /journal $>$

$</$ body $>$

A partir dessa estrutura básica, o depositante de metadados pode se orientar quanto à resolução de problemas, e informações mais avançadas também podem ser encontradas.

\section{Validação do arquivo XML}

Após a geração do arquivo de registro dos metadados, no caso da exportação não automática via OJS, é aconselhável sua validação mediante o esquema de dados requerido pela agência de registro. Para isso, a Crossref oferece um formulário web, denominado “Metadata Quality Check". O formulário, ilustrado na Figura 28, permite validar tanto a estrutura do arquivo quanto a qualidade dos metadados a serem depositados.

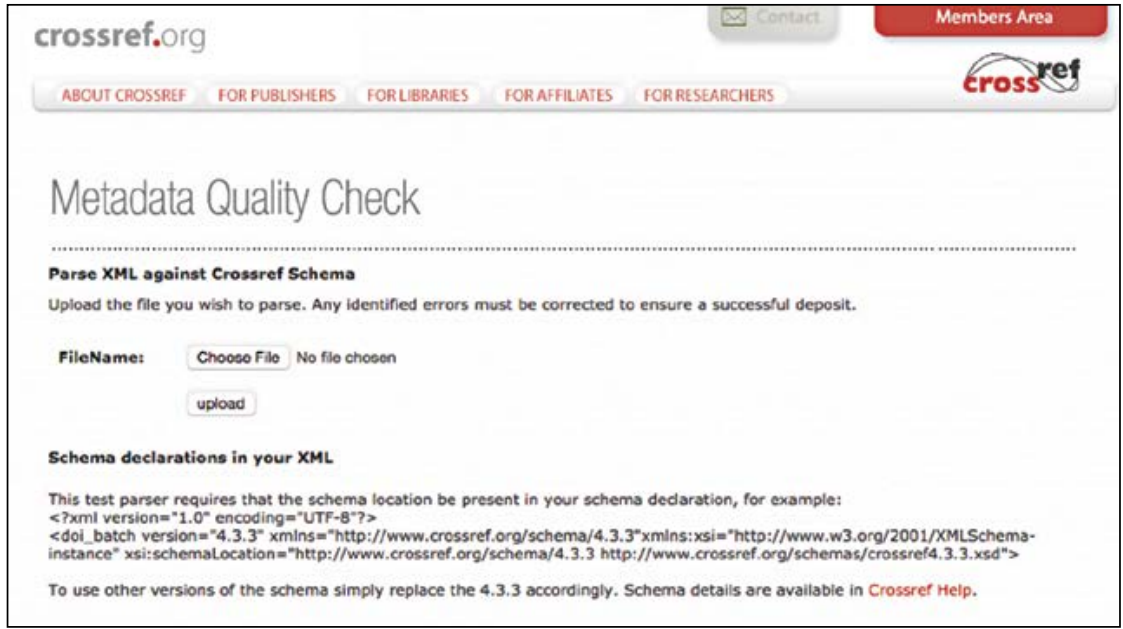

Figura 28 - Formulário de validação do arquivo $\mathrm{XML}^{13}$.

13.http://mww.crossref.org/O2publishers/parser.html 


\section{METADADOS SOBRE REFERÊNCIAS}

A Crossref pede que seja incluído nos metadados, quando existente, o nome DOI de documentos referenciados.

Entretanto, o OJS não inclui nos metadados depositados essa informação. Acredita-se que o OJS incluirá esse recurso no assistente de marcação de referências, mas atualmente não há previsão para tal funcionalidade. Desse modo, o editor pode depositar a informação manualmente, por meio de envio do arquivo XML complementar.

$\mathrm{O}$ arquivo consiste basicamente de uma referência ao DOI ao qual serão atribuídas as referências e uma lista de documentos citados, podendo ser representadas de diferentes formas, como demonstrado no exemplo a seguir, adaptado do manual da Crossref:

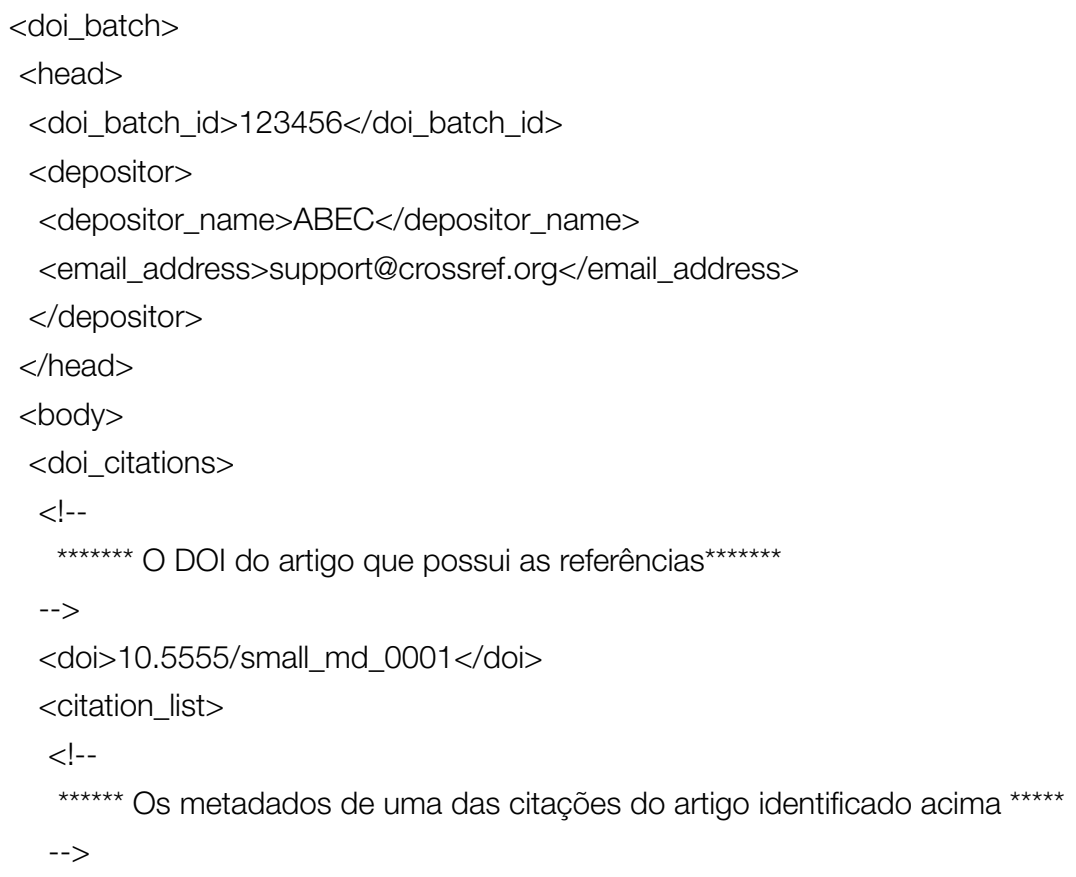


$<$ citation key="ref1">

$<$ journal_title>Current Opinion in Oncology</journal_title>

$<$ author>Chauncey</author>

$<$ volume $>13<$ /volume $>$

$<$ first_page $>21</$ first_page $>$

$<$ cYear $>2001<$ cYear $>$

$</$ citation $>$

$<!--$

${ }^{\star \star \star \star \star \star}$ Se o documento citado tiver DOI, basta inclui-lo desta forma ${ }^{\star \star \star \star \star}$

$->$

$<$ citation key="ref2">

$<$ doi $>10.5555$ /small_md_0001</doi>

$</$ citation $>$

$<!--$

${ }_{\star \star \star \star \star \star \star \star}$ É possível depositar referências de forma não estruturada

$->$

$<$ citation key="ref=3">

$<$ unstructured_citation>

Clow GD, McKay CP, Simmons Jr. GM, and Wharton RA, Jr. 1988. Climatological observations and predicted sublimation rates at Lake Hoare, Antarctica. Journal of Climate 1:715-728.

$</$ unstructured_citation>

$</$ citation $>$

$</$ citation_list $>$

$</$ doi_citations $>$

$</$ body $>$

$</$ doi_batch $>$

Para a elaboração do arquivo XML com as informações sobre referências, é possível utilizar o serviço de recuperação de nomes DOI da Crossref. Esse serviço permite buscar o nome DOI de determinado documento a partir de alguns campos de metadados, conforme apresentado na Figura 29. 


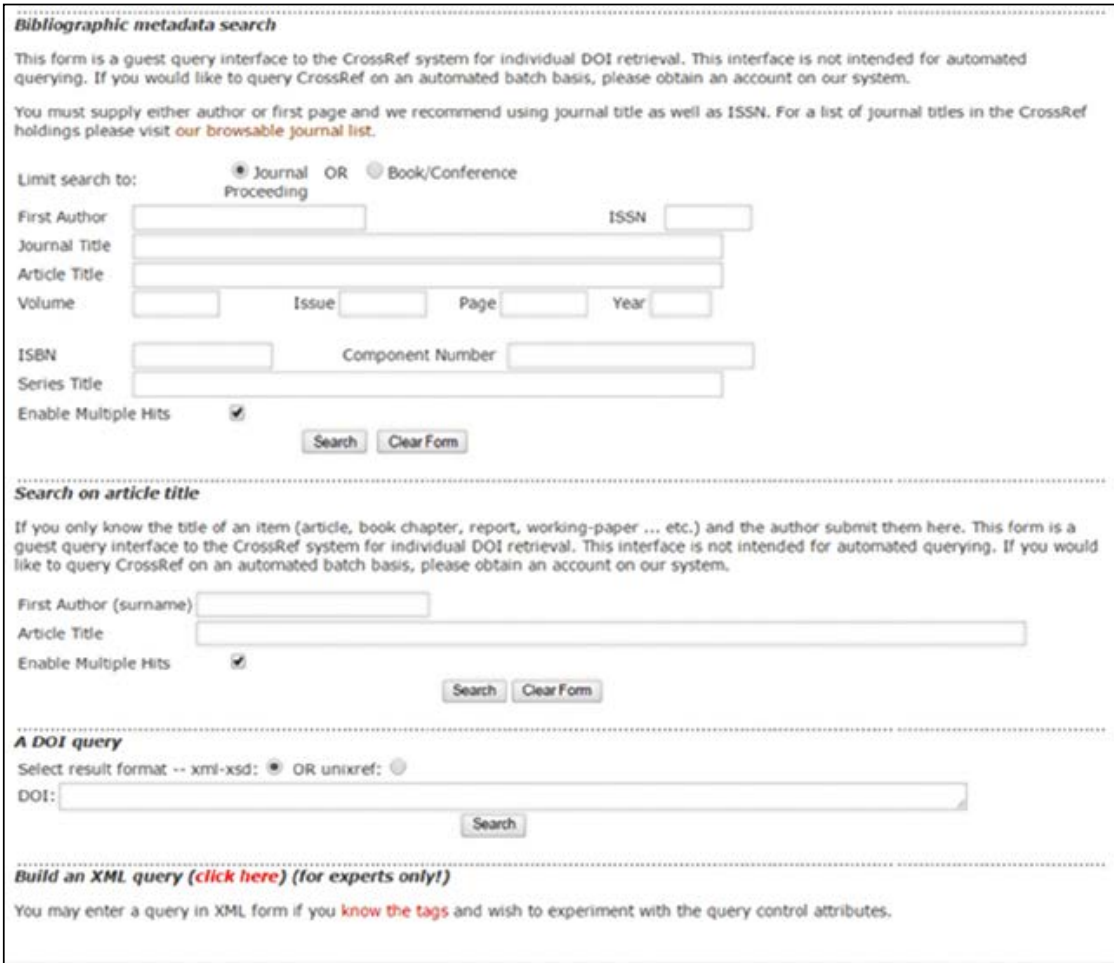

Figura 29 - Formulário para a busca de nomes DOI de documentos utilizados em referências.

\section{RESOLUÇÃO MÚLTIPLA}

Um serviço associado ao sistema DOI é a resolução múltipla. Normalmente, um nome DOI está associado a uma localização na web por meio de uma URL, sendo que o nome DOI, ao ser resolvido pelo sistema de resolução de nomes, direciona o usuário a essa localização.

Entretanto, como o nome sugere, a resolução múltipla refere-se ao caso em que um nome DOI pode direcionar para mais de um endereço na web. Na prática, consiste em um nome DOI com duas ou mais URLs associadas. É um recurso útil caso o objeto identificado esteja hospedado em duas bases ou em sistemas diversos, como no sistema de revistas e no repositório institucional, por exemplo. 
Ao acionar um nome DOI que possui resolução múltipla, o usuário é levado a uma página intermediária de escolha de qual versão do documento deseja acessar, conforme ilustrado na Figura 30.

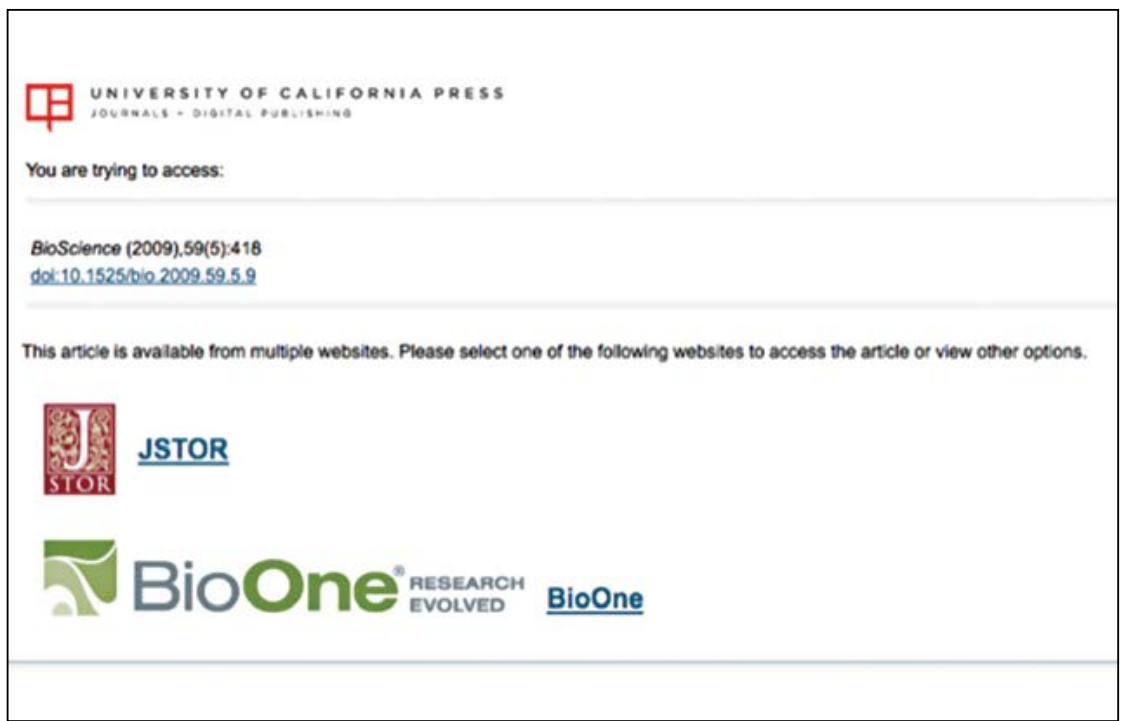

Figura 30 - Exemplo de resolução múltipla ${ }^{14}$.

Em termos práticos, a resolução múltipla permite que dois depositários cadastrem informações em determinado nome DOI. Um depositante primário envia os principais metadados, a URL, a página intermediária de resolução e autoriza depositantes secundários. Estes, por sua vez, podem enviar apenas URLs junto aos metadados do nome DOI.

\footnotetext{
14.http://mww.doi.org/doi_handbook/7_IDF.htm|
} 


\section{PROBLEMAS COMUNS}

Esta seção apresenta alguns dos problemas mais comuns encontrados pelos editores e os passos que auxiliam na sua solução.

\section{PROPRIEDADE DO PREFIXO}

A Crossref faz um controle de modo que cada ISSN esteja associado a apenas um prefixo em determinado momento, ou seja, cada ISSN pode pertencer a um prefixo somente. Assim, é possível que antes de receber um prefixo próprio, a revista contrate serviços de terceiros para a atribuição de nomes DOI a seus artigos, utilizando outro prefixo junto a seu ISSN. Tendo obtido um prefixo próprio, ao realizar seus depósitos, o editor receberá uma mensagem informando que seu ISSN está associado a outro prefixo, segundo o padrão:

ISSN “\{ISSN\}" has already been assigned to a different publisher \{publisher name $\}(\{$ publisher prefix $\})$

Caso seja necessário trocar de prefixo ou mudar um ISSN, é necessário entrar em contato a Crossref notificando a transferência do ISSN para o novo prefixo e listando os nomes DOI que devem ser transferidos.

\section{CONFLITOS DOI}

Os nomes DOI devem ser únicos para cada documento, não sendo recomendada a atribuição de dois nomes para um mesmo objeto. Para mais detalhes sobre conflitos DOI e sua resolução, consulte o documento DOI Conflicts definition, management and penalty fee policy ${ }^{15}$.

\section{NOMES DOI INVÁLIDOS APÓS O DEPÓSITO}

O depósito dos metadados, tanto manualmente - por meio de arquivo XML - quanto via OJS, pode demorar a ser processado. Ao ser enviado, o 
arquivo entra em uma fila de processamento que pode demorar alguns minutos ou horas, dependendo da quantidade de depósitos sendo realizados no momento.

Para verificar se seu arquivo já foi processado ou o seu lugar na fila de depósitos a serem processados, acesse o sistema, clicando no link "Show my submisison queue", disponível na página logo após o acesso. Esse link levará a uma tela onde o depósito é representado por uma linha na tabela, conforme a Figura 31, e pode ser identificado a partir do nome de usuário presente na coluna "Submitter".

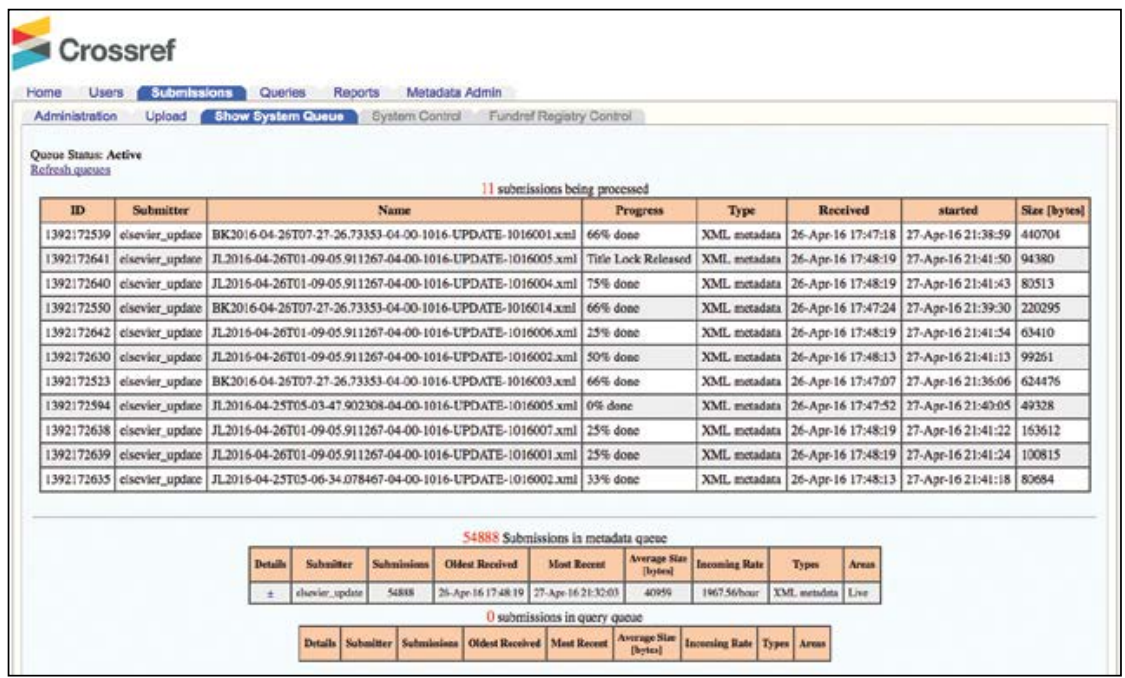

Figura 31 - Fila de depósitos a serem processados.

Após a submissão ter sido completamente processada e mesmo assim os nomes DOI permanecerem inválidos, é provável que erros tenham sido encontrados durante o processamento. Verifique então se existem erros nas submissões, como indicado no tópico "Acompanhamento do depósito".

\section{DATA DE PUBLICAÇÃO NÃO CADASTRADA}

Ao registrar os artigos, o sistema exibe uma mensagem no canto superior direito da tela informando: "A data de publicação está ausente para o artigo de ID <número do artigo>", conforme exemplificado na Figura 20. 
Esse erro pode ser decorrente de diferentes causas e impedirá o processamento do depósito na Crossref, sendo necessário corrigi-lo antes de prosseguir com o envio de metadados.

No caso, para inserir a data de publicação do artigo, é preciso encontrá-lo no sistema e acessar sua página de "Edição", selecionando as datas de publicação nos campos correspondentes, conforme indicado na Figura 33.

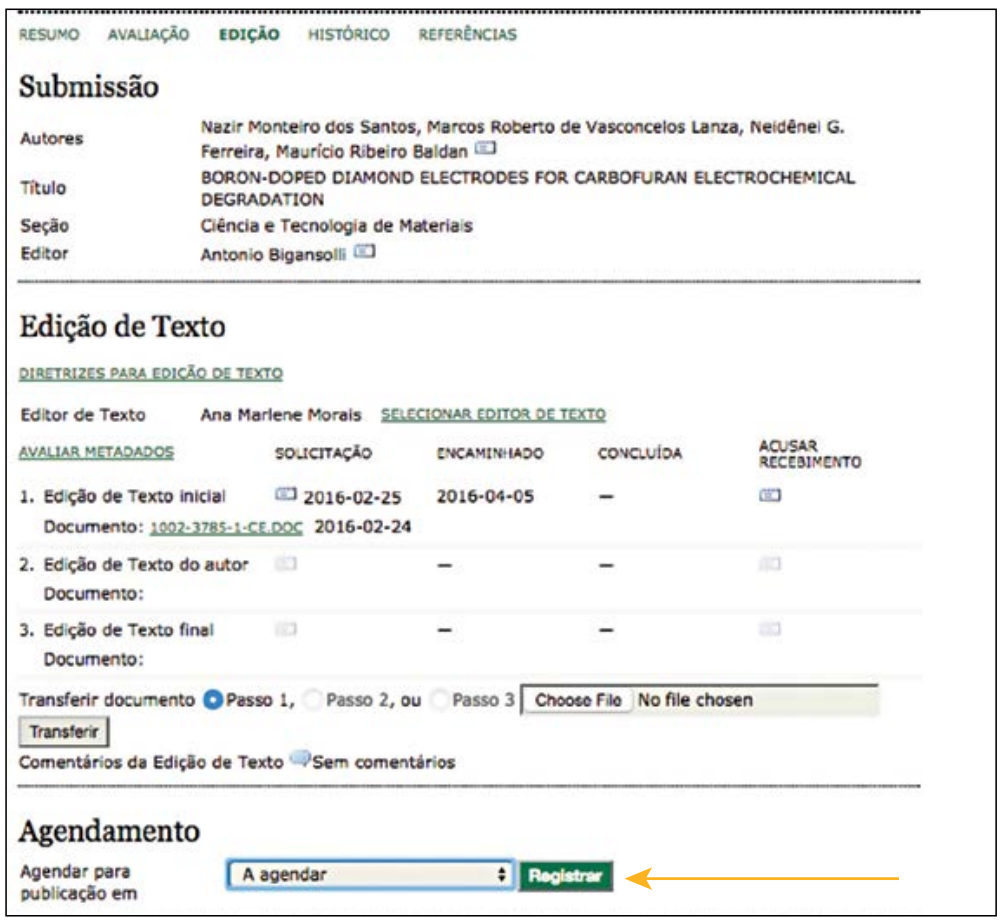

Figura 32 - Registro da data de publicação.

\section{ONDE OBTER AJUDA}

Diferentes fontes de documentação e apoio podem ser acessadas em caso de dúvidas ou questionamentos não apresentados aqui. Este Guia consiste em uma versão atualizada da cartilha Atribuição de identificadores digitais para publicações científicas: DOI para SEER/OJS ${ }^{16}$, publicado pelo Ibict em 2013.

\footnotetext{
16.http://livroaberto.ibict.br/bitstream/1/1016/7/Atribui\%C3\%A7\%C3\%A30\%20de\%2Oidentificadores\%20 digitais\%20para\%20publica\%C3\%A7\%C3\%B5es\%20cient\%C3\%ADficas.pdf
} 
Além destas publicações o Ibict oferece um fórum onde se pode obter auxílio quanto ao uso do identificador digital e de outras tecnologias associadas à comunicação científica, permitindo a troca de dúvidas e soluções relacionadas ao DOI.

também a International DOI Foundation oferece como fonte de documentação o DOI Handbook ${ }^{17}$, o qual apresenta conceitos, regras e políticas que compõem o sistema DOI em geral.

E, especificamente, no caso de DOIs registrados na Crossref, a agência oferece um manual on-line $e^{18}$, que cobre todos os detalhes relacionados ao depósito de metadados, recuperação e demais serviços implementados.

\footnotetext{
17.http://www.doi.org/doi_handbook/7_IDF.html

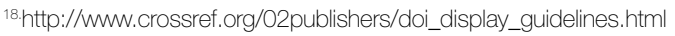




\section{OUTROS IDENTIFICADORES PERSISTENTES}

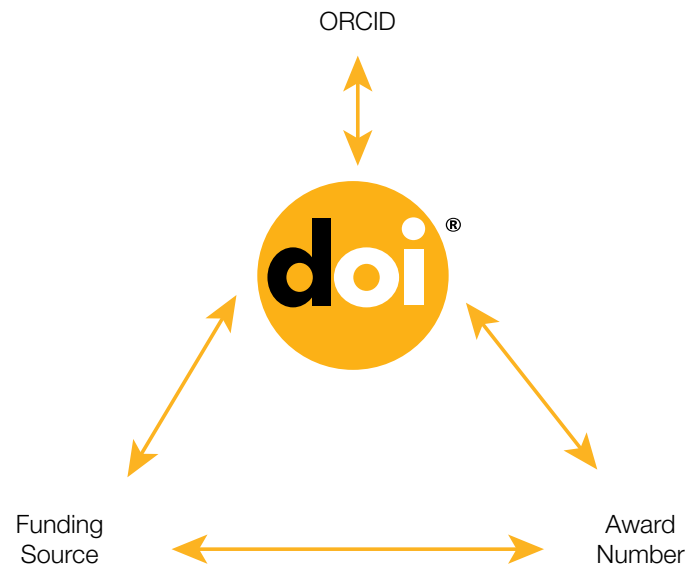

\section{Crossref}

A adoção de medidas visando melhores práticas editoriais que incluam aumentar a transparência das informações está fazendo com que se tenha de colaborar com algumas tarefas de interoperabilidade, como nos casos em que as agências de fomento, por exemplo, pedem aos autores para armazenar e citar dados de pesquisa ou mesmo atribuir DOIs de dados suplementares aos artigos publicados.

Abordaremos uma questão que já vem sendo exigida em algumas instâncias: a de um identificador persistente para autor. Nas versões atuais do OJS, já é solicitado ao autor, na hora de se registrar no periódico, que tenha e inclua um identificador ORCID. Mas o que é esse identificador e para que serve?

ORCID é um identificador digital persistente para o autor. Esse identificador está para o autor assim como o DOI está para um documento digital, podendo ser conectado a vários tipos de produção de pesquisa, incluindo artigos de periódicos, livros, teses, patentes, entre outros. É um código alfanumérico 
de 16 caracteres, lançado em Outubro de 2012, que tem a finalidade de diferenciar um autor de qualquer outro, ainda que tenha homônimo ou tenha publicado, sido citado e/ou indexado de formas variadas. O ORCID identifica um único autor fazendo conexão automática com toda sua produção científica, onde quer que tenha sido publicada. O cadastro para obtenção dos ORCIDs é gratuito e poderá ser feito individualmente ou pela instituição (Figura 34). É um código interoperável com outros sistemas ID, permitindo importação/ exportação de dados, por exemplo, com o ResearcherID, sistema proprietário da Thomson Reuters.

Algumas universidades brasileiras, agências de fomento e editoras conectam (em alguns casos, exigem) ORCIDs em seus fluxos de trabalho, ou seja, já vêm adotando como prática o uso dos identificadores persistentes de autores para fazer a coleta da produção científica de seus colaboradores. As agências de registro, como a Crossref, estão viabilizando bancos de dados que armazenem metadados provenientes do ORCID, FundRef, Open Indicador Access, entre outros. Também já estão sendo criadas APIs e interfaces de busca para esses novos tipos de dados.

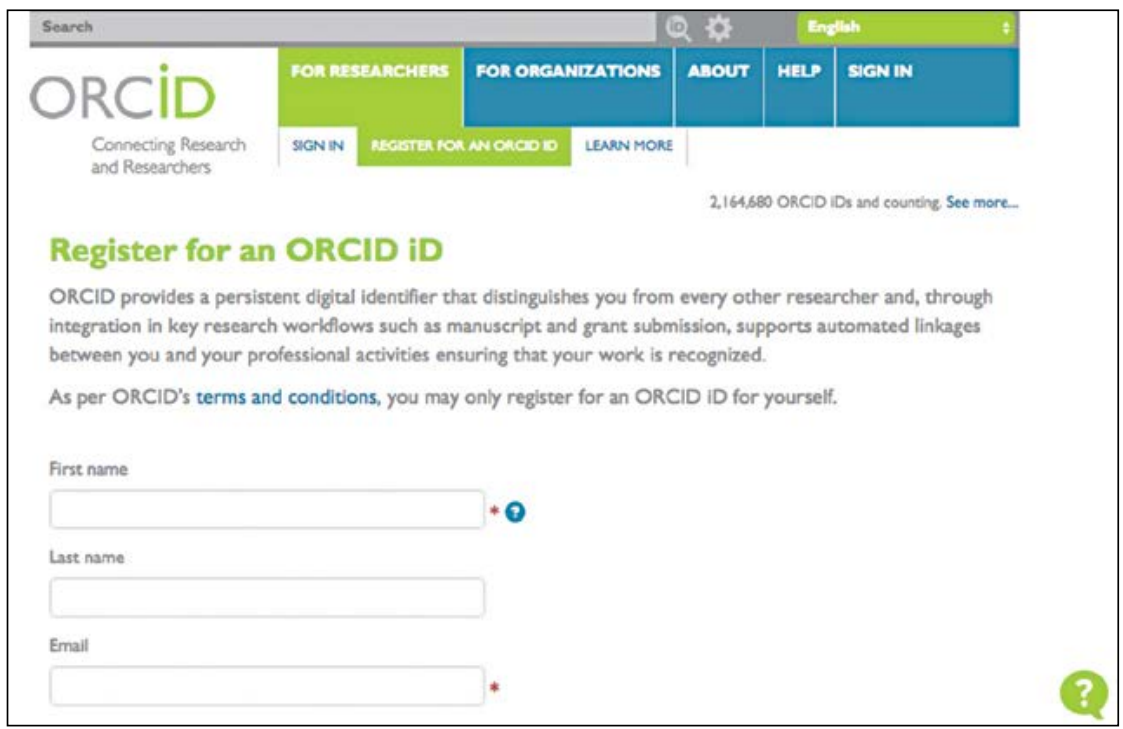

Figura 33 - Cadastro de ORCID. 


\section{VANTAGENS AO AUTOR}

As vantagens ao autor são: a certeza de que a sua pesquisa não será erroneamente atribuída a outra pessoa com um nome semelhante; maior facilidade para as pessoas encontrarem e compartilharem o trabalho; um identificador único que pode ser utilizado ao longo de toda a carreira.

Após gerar seu código, o autor poderá obter, na sua área de registro, o ORCID em Quick Response Code (QR-Code) para publicá-lo no seu VCard, site, blog, Facebook, etc. O QR-Code é um código de barras bidimensional que, mediante leitura por um dispositivo móvel com câmera, facilita o acesso a sites, textos, localização em espaços georreferenciados, importação dos dados de um contato para agenda do celular etc. Isto facilitará a colocação do ORCID em QR-Code no seu VCard, site, blog ou Facebook e ajudará seu leitor encontrar toda sua produção científica em um único lugar. 


\section{SOBRE OS AUTORES}

\section{RONNIE FAGUNDES DE BRITO}

Tecnologista do Instituto Brasileiro de Informação em Ciência e Tecnologia. Bacharel em Sistemas de Informação pela Universidade Federal de Santa Catarina (UFSC). Mestre e Doutor em Engenharia e Gestão do Conhecimento pela Universidade Federal de Santa Catarina. Tem experiência na área de Engenharia de Produção, com ênfase em Mídia e Conhecimento na Educação e Acessibilidade. Atua na promoção de ferramentas para o acesso aberto e gestão da informação científica.

\section{MILTON SHINTAKU}

Tecnologista do Instituto Brasileiro de Informação em Ciência e Tecnologia. Mestre e Doutor em Ciência da Informação pela Universidade de Brasília (UnB). Coordena a Coordenação de Articulação, Geração e Aplicação de Tecnologia no Ibict, atuando no apoio à utilização de ferramentas para gestão da informação. Tem experiência no apoio ao desenvolvimento de repositórios e outros canais de disseminação da informação.

\section{SUELY DE BRITO CLEMENTE SOARES}

Sócia proprietária da empresa Content Mind Capacitação Profissional. Graduada em Biblioteconomia pela Pontifícia Universidade Católica de Campinas (PUC-Campinas). Especialista em Administração de Bibliotecas Universitárias pela Universidade de Brasília. Mestre em Educação, Ciência e Tecnologia pela Faculdade de Educação da Universidade Estadual de Campinas (Unicamp). É Professora das disciplinas Bibliotecas Digitais e Cultura Digital no MBA em Gestão de Unidades de Informação do Centro Universitário Central Paulista (Unicep). Palestrante e Professora de EaD desde 2000. Docente em cursos presenciais e a distância nos temas de sua especialidade. Bibliotecária aposentada da Universidade Estadual Paulista "Júlio de Mesquita Filho" (Unesp), campus de Rio Claro, SP. Atua na área de Ciência da Informação, com ênfase em Biblioteconomia, principalmente nos temas: capacitação profissional de bibliotecários, comunidades virtuais de aprendizagem colaborativa, EaD, MOOCs, bibliotecas e repositórios digitais, publicação de periódicos eletrônicos em OJS/SEER, de eventos em OCS/SOAC, arquivos abertos, tecnologias de informação e comunicação, bases de dados on-line, normalização documentária, revisão de originais, redação acadêmica para a web 2.0 e redes sociais.

\section{CLAUDIANE WEBER}

Bibliotecária na Universidade Federal de Santa Maria (UFSM). Pós-Graduada em Psicologia Aplicada pela Universidade Estatal de São Petersburgo, Rússia. Mestre em Engenharia de Produção pela UFSM (2010). Doutoranda em Ciência da Informação pela Escola de Comunicação e Artes da Universidade de São Paulo (USP). É Professora na Faculdade Antonio Meneghetti, onde também é editora da Revista Saber Humano. Realiza estudos para aplicação do DOI e demais ferramentas da Crossref para periódicos. Trabalhou com a difusão do acesso livre à informação científica brasileira, junto ao Sistema de Bibliotecas da UFSC, desenvolvendo e auxiliando a coordenação do repositório institucional. Foi professora nos cursos de graduação em Arquivologia e Biblioteconomia na Universidade Federal de Santa Catarina. Tem experiência em ambientes virtuais de aprendizagem, gestão de portais e repositórios científicos. 
INSTITUTO BRASILEIRO DE

INFORMAÇÃO EM CIÊNCIA E TECNOLOGIA (Ibict)

Diretoria

Cecília Leite Oliveira

Coordenação-Geral de Pesquisa e Desenvolvimento de Novos Produtos (CGPD)

Arthur Fernando Costa

Coordenação-Geral de Pesquisa e Manutenção de Produtos Consolidados (CGPM)

Lillian Alvares

Coordenação-Geral de Tecnologias de Informação e Informática (CGTI)

Leonardo Lazarte

Coordenação de Ensino e Pesquisa, Ciência e Tecnologia da Informação (COEP)

Lena Vania Ribeiro Pinheiro

Coordenação de Editoração (COED)

Ramón Martins Sodoma da Fonseca

Coordenação de Articulação, Geração e Aplicação de Tecnologia (COAT)

Milton Shintaku

ASSOCIAÇÃO BRASILEIRA DE EDITORES CIENTÍFICOS (ABEC Brasil)

Presidente

Rui Seabra Ferreira Junior

CEVAP/Unesp - Botucatu (SP)

Vice-Presidente

Ana Marlene F. Morais

IAE - São José dos Campos (SP)

Secretário-Geral

Suely de Brito C. Soares

Unesp (aposentada) - Rio Claro (SP)

10 Secretário

Milton Shintaku

Ibict - Brasília (DF)

$1^{\circ}$ Tesoureiro

Benedito Barraviera

FMB/Unesp - Botucatu (SP)

$2^{\circ}$ Tesoureiro

Suzana Caetano S. Lannes

FCF/USP - São Paulo (SP)

Presidente anterior

Sigmar de Mello Rode

ICT/Unesp - São José dos Campos/SP 
